\title{
Article \\ Thickness Effect on Some Physical Properties of RF Sputtered ZnTe Thin Films for Potential Photovoltaic Applications
}

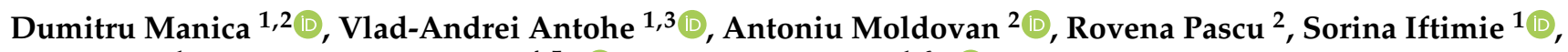 \\ Lucian Ion ${ }^{1}$, Mirela Petruta Suchea $4,5, *$ (D) and Ştefan Antohe 1,6,*(D) \\ 1 Faculty of Physics, University of Bucharest, 077125 Magurele, Romania; dumitru.manica@inflpr.ro (D.M.); \\ vlad.antohe@fizica.unibuc.ro (V.-A.A.); sorina.iftimie@fizica.unibuc.ro (S.I.); \\ lucian@solid.fizica.unibuc.ro (L.I.) \\ 2 National Institute for Laser, Plasma and Radiation Physics, 077125 Magurele, Romania; \\ antoniu.moldovan@inflpr.ro (A.M.); rovena.pascu@inflpr.ro (R.P.) \\ 3 Institute of Condensed Matter and Nanosciences, "Université Catholique de Louvain", \\ B-1348 Louvain-la-Neuve, Belgium \\ 4 Center of Materials Technology and Photonics, School of Engineering, Hellenic Mediterranean University, \\ 71410 Heraklion, Greece \\ 5 National Institute for Research and Development in Microtechnologies, 023573 Bucharest, Romania \\ 6 Academy of Romanian Scientists, 050044 Bucharest, Romania \\ * Correspondence: mirasuchea@hmu.gr or mira.suchea@imt.ro (M.P.S.); santohe@solid.fizica.unibuc.ro (Ş.A.)
}

check for

updates

Citation: Manica, D.; Antohe, V.-A.; Moldovan, A.; Pascu, R.; Iftimie, S.; Ion, L.; Suchea, M.P.; Antohe, Ş.

Thickness Effect on Some Physical Properties of RF Sputtered ZnTe Thin Films for Potential Photovoltaic Applications. Nanomaterials 2021, 11, 2286. https://doi.org/10.3390/ nano11092286

Academic Editor: Christian Mitterer

Received: 5 August 2021

Accepted: 31 August 2021

Published: 2 September 2021

Publisher's Note: MDPI stays neutral with regard to jurisdictional claims in published maps and institutional affiliations.

Copyright: (c) 2021 by the authors. Licensee MDPI, Basel, Switzerland. This article is an open access article distributed under the terms and conditions of the Creative Commons Attribution (CC BY) license (https:/ / creativecommons.org/licenses/by/ $4.0 /)$.

\begin{abstract}
Zinc telluride thin films with different thicknesses were grown onto glass substrates by the rf magnetron sputtering technique, using time as a variable growth parameter. All other deposition process parameters were kept constant. The deposited thin films with thickness from 75 to $460 \mathrm{~nm}$ were characterized using X-ray diffraction, electron microscopy, atomic force microscopy, ellipsometry, and UV-Vis spectroscopy, to evaluate their structures, surface morphology, topology, and optical properties. It was found out that the deposition time increase leads to a larger growth rate. This determines significant changes on the ZnTe thin film structures and their surface morphology. Characteristic surface metrology parameter values varied, and the surface texture evolved with the thickness increase. Optical bandgap energy values slightly decreased as the thickness increased, while the mean grains radius remained almost constant at $\sim 9 \mathrm{~nm}$, and the surface to volume ratio of the films decreased by two orders of magnitude. This study is the first (to our knowledge) that thoroughly considered the correlation of film thickness with ZnTe structuring and surface morphology characteristic parameters. It adds value to the existing knowledge regarding ZnTe thin film fabrication, for various applications in electronic and optoelectronic devices, including photovoltaics.
\end{abstract}

Keywords: ZnTe; thin films; rf-magneton sputtering; AFM; surface metrology; thickness effect

\section{Introduction}

There is a need for new nanostructured materials with enhanced properties, due to the development of new systems and materials that use nanotechnologies. Due to characteristics obtained at the time of the deposition process such as: low resistivity, high transparency in the visible spectrum, etc. [1-4], thin layers of zinc telluride (ZnTe) are used in various modern technologies, which are implemented in various micro- and nanostructured devices, such as light emitting diodes, solar cells, photodetectors, etc. [1-18]. Although it is a popular material, there are few publications and studies regarding its material engineering. ZnTe is a sensitive material in the green spectral region, with a bandgap of $2.26 \mathrm{eV}$ and a low electronic affinity of $3.53 \mathrm{eV}$; it can be used as a p-type buffer material in hetero-junction solar cells based on CdTe [10-13,18]. It can be used as back contact material to CdTe-based solar cells [14] in a multilayer device. It is a precious material from an ecological point of view; it can be used as a replacement for the CdS 
window layer [15]; the "condition" is that the conductivity is n-type. For the deposition of thin layers [16-20], more physical and chemical growth paths are known, such as molecular beam epitaxy (MBE) [21], chemical bath deposition (CBD), electron-beam evaporation, thermal evaporation, magnetron sputtering [12], and electrodeposition [19-22]. The ZnTe thin layer properties depend directly on the deposition method, deposition conditions, and the growth direction imposed by the substrate when the substrate is crystalline $[5-8,23]$. Some studies have established the ideal deposition conditions for various deposition methods, to obtain ZnTe layers with the necessary physical properties, a well-defined morphology, and crystal structure, but there is no systematic reproducible technology available for high performance ZnTe coating fabrications [2-9,24,25]. In this context, studies regarding correlation for growth conditions/parameters with ZnTe structuring and morphology, in correlation with their physical properties, are still very important.

ZnTe thin films presented in this scientific report were prepared by rf magnetron sputtering, varying the deposition time that was related to the deposition rate, and finally determining the film thickness. Depending on the selected conditions, we sought to obtain an intermediate layer for the formation of junctions and the facilitation of electric charge transfer, which can be used directly in multilayer solar cells. In order to understand the ZnTe film structuring during growth, the investigation was centered on structure and surface morphology evolution, and the surface characteristic parameters correlation with material optical properties, and how it changed depending on the deposition parameters. For this scope, the following characterization methods were used: scanning electron microscopy (SEM), X-ray diffraction (XRD), atomic force microscopy (AFM), ellipsometry (spectroelipsometer-SE), and UV-Vis absorption spectroscopy. SEM was used for films thickness evaluation in the cross section while XRD was used to verify material crystallinity. AFM in non-contact mode was used to characterize the surface morphology and topology. A WVASE spectroelipsometer with variable incidence angles $\left(60^{\circ}, 65^{\circ}\right.$, and $\left.70^{\circ}\right)$ was used for optical characterization. Optical models were generated by WVASE32 software; the parameters $\mathrm{n}$ (refractive index), $\mathrm{k}$ (extinction coefficient), and roughness were measured by mounting the ellipsometer parameters Psi $(\Psi)$ and delta $(\Delta)$.

\section{Experimental Procedures}

\subsection{Fabrication Technique}

Magnetron sputtering is an easy-to-use deposition method. Due to the simplicity and easy handling of the installation, it allows good control of the deposition parameters. These parameters are enclosure pressure, substrate target distance, substrate temperature, applied power in the deposition process, deposition time, etc. ZnTe thin films were grown onto BK7 optical glass substrates (Heinz Herenz, Hamburg, DE6, Germany). Prior to any deposition process, the substrates were cleaned in acetone (Chim Reactiv S.R.L., Bucharest, BUC, Romania) and isopropyl alcohol (Chim Reactiv S.R.L., Bucharest, BUC, Romania) for $15 \mathrm{~min}$, for each procedure, and then were rinsed in deionized water dried under nitrogen flow.

For all fabricated samples, the substrate-target distance, working pressure, substrate temperature, and applied power were maintained constant at $10 \mathrm{~cm}, 0.86 \mathrm{~Pa}, 250{ }^{\circ} \mathrm{C}$, and $100 \mathrm{~W}$, respectively, and the deposition time varied at 5, 10, 15, and $20 \mathrm{~min}$. For ease of discussion, in the whole manuscript, the samples were denoted ZnTe1 (5 min), ZnTe2 (10 min), ZnTe3 (15 min), and ZnTe4 (20 min).

\subsection{Characterization Methods}

In order to characterize the obtained thin layers, various characterization techniques were involved. The characterization techniques used were SEM, AFM, UV-Vis, SE, and XRD.

\subsubsection{Morphological and Structural Characterization}

SEM was used to study the film cross sections and to estimate their thickness. While AFM was used for detailed characterization of film surfaces. 


\subsubsection{SEM Characterization}

The SEM cross-section micrographs were obtained in high vacuum by using a Tescan Vega XMU-II electron microscope (Brno-Kohoutovice, B, Czech Republic) operating at $30 \mathrm{kV}$ with a detector for secondary electrons.

\subsubsection{AFM Characterization}

The morphology of the surface was analyzed by AFM topography measurements using a XE100 AFM, from Park Systems (Suwon, Republic of Korea). The measurements were carried out in a noncontact mode, using silicon cantilevers (PPP-NCHR, Nanosensors, Neuchatel, Switzerland). The surface was scanned into various areas of the films with sizes of $5 \mu \mathrm{m} \times 5 \mu \mathrm{m}$ and $2 \mu \mathrm{m} \times 2 \mu \mathrm{m}$. The surface roughness characteristic parameters were estimated using the AFM software while the surface topology specific parameters and texturing were evaluated by using Gwyddion version 2.49 (2017) open access specialized SPM software [26].

\subsubsection{X-ray Diffraction}

The structural features of fabricated ZnTe films were investigated by XRD, using a Bruker D8 Discover diffractometer from Brucker (Bruker Nano GmbH Am Studio 2D, 12489 Berlin, Germany) using CuK $\alpha=1.54 \AA$ radiation in Bragg-Brentano theta-theta geometry. The scattered $X$-ray photons from samples were recorded in the $2 \theta$ range of $20-70^{\circ}$ with a scanning rate of $0.04^{\circ} / \mathrm{s}$ at room temperature.

\subsubsection{Optical Characterization}

Spectrophotometry (UV-Vis)

The optical properties of thin films depend on the structure, composition, and physical and chemical properties of the material. Using UV-Vis optical spectroscopy, information about the structure of energy levels and bands and photoconduction mechanisms can be obtained. UV-Vis optical spectroscopy transmission measurements were performed in the wavelength ranges of 300-1500 nm, at room temperature, using a Lambda 750 spectrophotometer from Perkin Elmer (Norwalk, CT, USA).

\section{Ellipsometry}

One of the widely used characterization methods was ellipsometry. For the optical characterization of ZnTe samples, a Spectro-ellipsometer WVASE, (Lincoln, NE, USA) was used, with variable angels of incidence $\left(60^{\circ}, 65^{\circ}\right.$, and $\left.70^{\circ}\right)$, for optical characterization, having high accuracy and precision with a wide spectral range of 250-1700 nm. Optical models were generated by WVASE32 software; n, k parameters, and roughness were measured by fitting the Psi $(\Psi)$ and delta $(\Delta)$ parameters.

\section{Results and Discussions}

\subsection{SEM Microscopy Analysis—Film Thickness Evaluation}

All samples were characterized by SEM microscopy as described above. The SEM analysis shows the effect of the deposition parameters on the material structuring. For example, Figure 1 presents representative images of layers grown under similar conditions, except for the variation of the deposition time. One can see from the SEM characterization how the structuring evolves when the deposition time changes. The ZnTe layers are compact with a relatively constant thickness. Some large asperities can be observed on the thinner film surface. As the film grows, the surface becomes cleaner and the layers seem to become more compact. Using the SEM analyses options, the local thickness of the ZnTe layers deposited by rf magnetron sputtering vas estimated. To evaluate film thicknesses, a mean value was calculated using local values, measured as shown in the examples presented in Figure 1, in different locations along the substrate lengths. Mean thickness values (calculated as the arithmetic average of various local thickness measured along the cross sections of each film) were estimated to be ZnTe1 (5 min) $75 \mathrm{~nm}$, ZnTe2 
(10 min) $154 \mathrm{~nm}, \mathrm{ZnTe} 3(15 \mathrm{~min}) 251 \mathrm{~nm}$, and ZnTe4 (20 min) $461 \mathrm{~nm}$, respectively, with an error bar of $\pm 10 \%$ for each value.
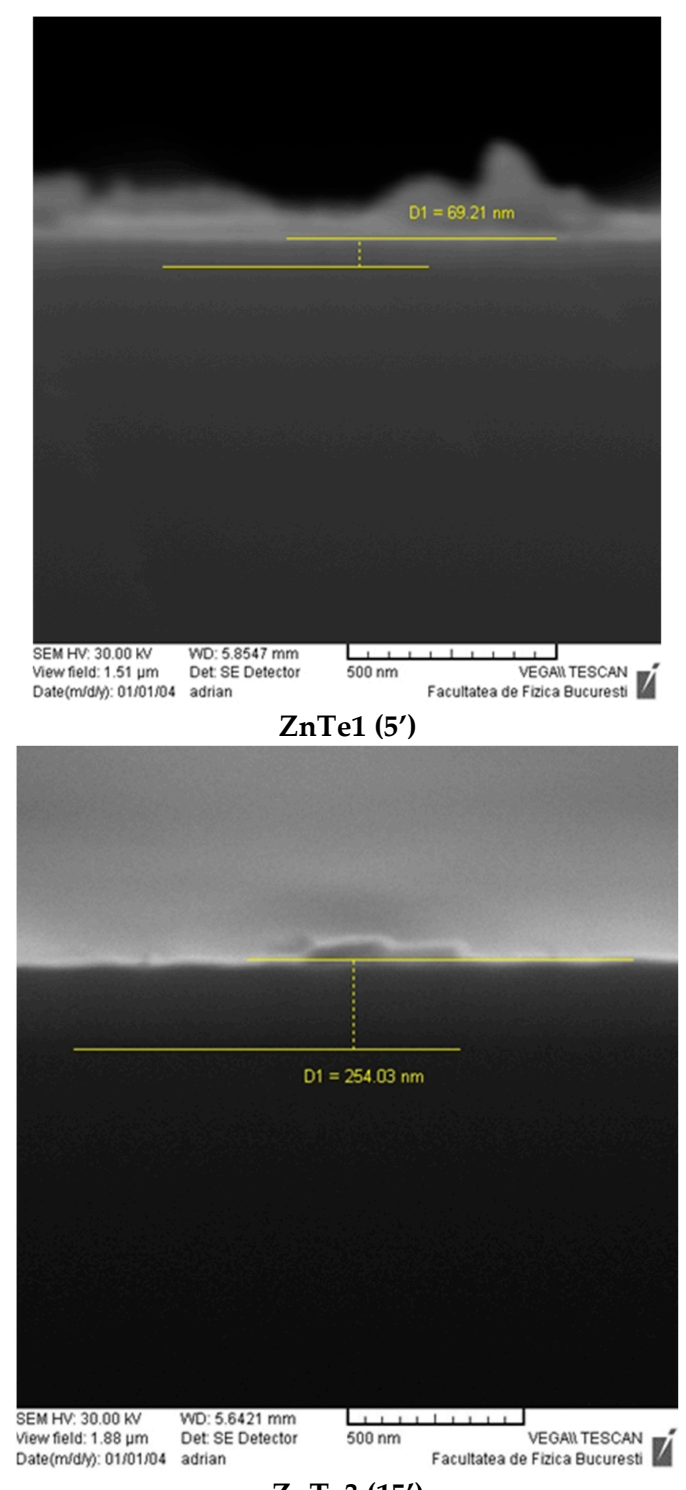
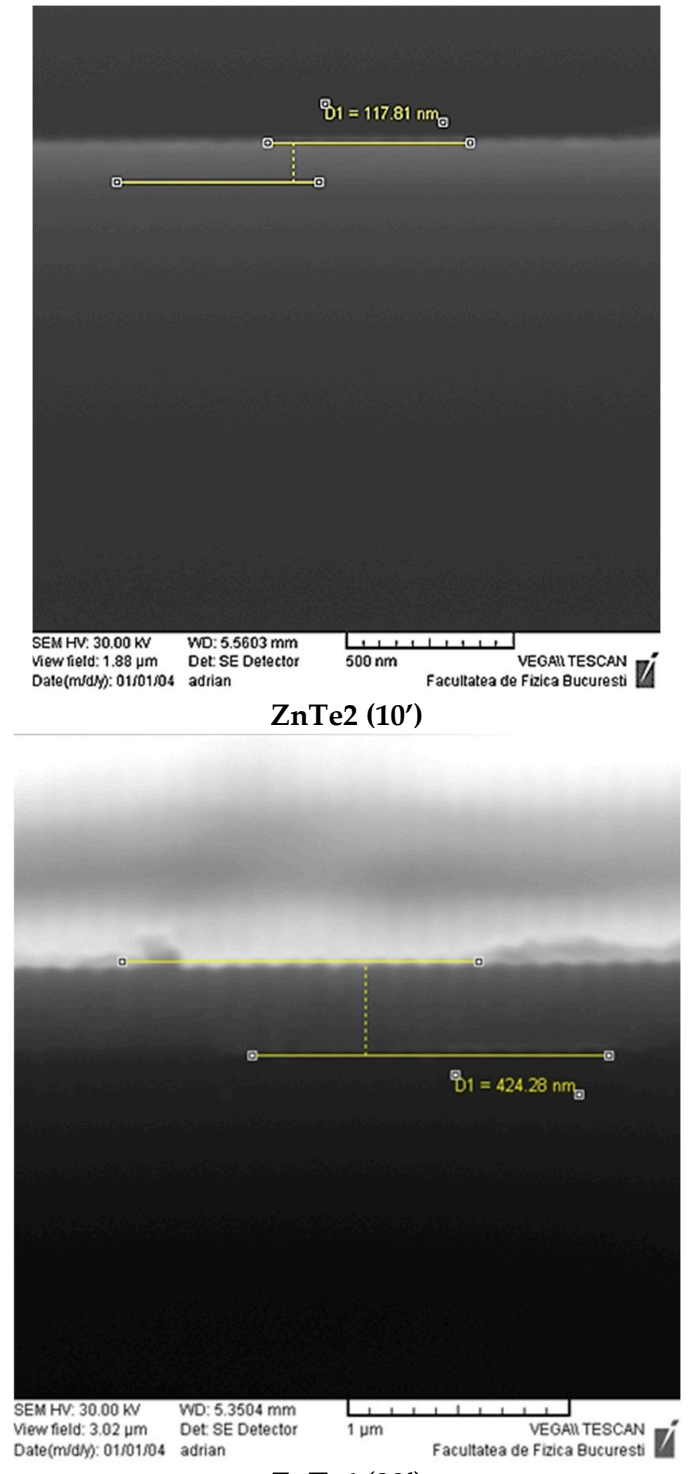

ZnTe4 (20')

Figure 1. Examples of SEM images of cross sections of the fabricated ZnTe thin films (a local thickness estimation for each kind of film - the difference from the average values is due to local variations and it is in the errors limits).

It was noticed that, with the increase of the deposition time, the thickness of the thin layers also changed. It can be observed that the growth rate slightly increased from $15 \mathrm{~nm} / \mathrm{min}$ for $5 \mathrm{~min}$ growth time; $15.4 \mathrm{~nm} / \mathrm{min}$ for $10 \mathrm{~min} ; 16.3 \mathrm{~nm} / \mathrm{min} 15 \mathrm{~min}$ and becomes $23 \mathrm{~nm} / \mathrm{min}$ for the thickest film. The increase of the growth rate in time can be attributed to the evolution of the growth mechanism of the films onto the substrate. In the early stage of nucleation, an island growth mechanism is present. This growth can be noticed when the adherence between the atom to atom is greater than the bonding between the substrate and the adatoms; it was observed on the thinnest films where the film was rough, island-like structured, and the thickness had larger variations across the substrate. At longer deposition times, the adatoms begin to accumulate; migration took place and the ZnTe layers with enhanced crystallinity were formed, as can be seen in Figure 1, and confirmed further by XRD analysis (see Section 3.2. Structural Characterization, X-ray Diffraction). 


\subsection{Structural Characterization, X-ray Diffraction}

$X$-ray diffraction patterns were recorded and diffractograms for the samples were obtained at different deposition times: 5, 10, 15, and $20 \mathrm{~min}$, labeled as ZnTe-5 min, ZnTe-10 min, ZnTe-15 min, and ZnTe-20 min, are presented in Figure 2. Diffraction features located at $25.24^{\circ}, 42.34^{\circ}$, and $49.59^{\circ}$ can be assigned unambiguously to (111), (220), and (311) reflections of the cubic ZnTe phase, according to the JCPDS database, card no. 01-0582. Therefore, ZnTe thicker films are polycrystalline with the respective zincblende structures. It can be observed that features are amorphous bands at 5 and $10 \mathrm{~min}$, and evolve to diffraction peaks at 15 and $20 \mathrm{~min}$. We should note that, at these stages, the chemical reaction of $\mathrm{Zn}$ with Te was complete, even if the crystal quality was poor-no $\mathrm{Zn}$ metallic phase or shift on the peak position can be observed. The evolution of the crystallinity at different stages of growth suggests the existence of a relationship between the crystal quality and the layer thickness, as a result of different deposition times. An increase of the crystallite size with the thickness for ZnTe films was also reported by Aboraia et al. [23], where films of different thicknesses were obtained by plasma immersion $\mathrm{O}^{-}$ion implantation. The Scherrer equation was used so we could get a quantitative idea about the crystal quality. This equation relates the peak broadening by the crystal quality in the following way [24]:

$$
\tau=\frac{k \lambda}{\beta \cos \theta}
$$

where $k$ is the shape factor taken as 0.9 , taking into account the spherical form of the grains, as shown in AFM images, $\lambda=0.154 \mathrm{~nm}$ is the wavelength of the $X$-rays and $\theta$ is the angular position. In the case of deposition times of 5 and $10 \mathrm{~min}$, the diffraction features are amorphous and the Scherrer equation becomes inapplicable, at higher times (e.g., 15 and $20 \mathrm{~min}$ ), the peak broadening on ZnTe (111) is $1.63^{\circ}$ and $0.89^{\circ}$, respectively. Applying Equation (1), the mean crystallite size is 5.0 and $9.1 \mathrm{~nm}$. At the same time, the position of the diffraction peaks remains unchanged, which indicates that the interplanar distances are preserved (e.g., $d_{111}=0.35 \mathrm{~nm}, \mathrm{~d}_{220}=0.21 \mathrm{~nm}$, and $\mathrm{d}_{311}=0.18 \mathrm{~nm}$ according to Bragg's law) for different deposition times. By applying the standard relation between the interplanar distances and the lattice constant for cubic crystals [25], it was found that the unit cell parameter is $0.61 \mathrm{~nm}$. As a conclusion, the XRD findings indicate that the different deposition times lead to different sizes for the crystalline domains for ZnTe, while the unit cell parameter remains unchanged. This can be further ascribed to a constant lattice strain at different stages of formation for ZnTe films.

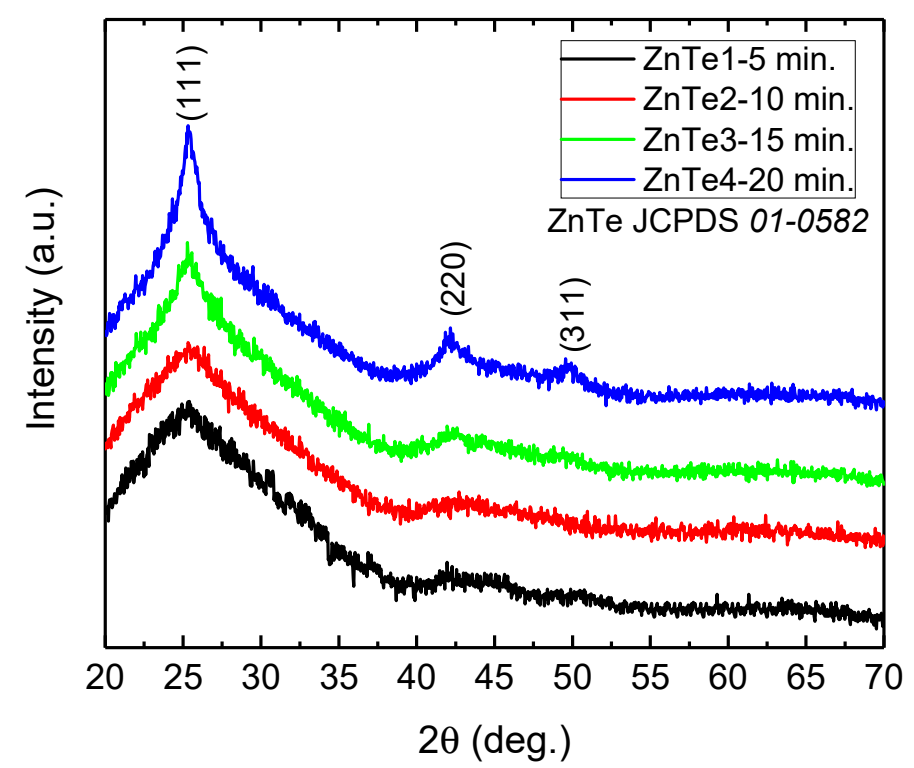

Figure 2. X-ray diffractograms of ZnTe films with different thicknesses. 


\subsection{AFM Characterization}

AFM characterization of ZnTe thin films with different thicknesses show that all films have a granular structure that evolve as thickness increases. As can be observed from the two-dimensional (2D) $2 \mu \mathrm{m} \times 2 \mu \mathrm{m}$ images presented in Figure 3, the thickness increase led to surfaces with a much smaller z-range fact, meaning surface flattening and smoothening. Using Gwyddion software, manual surface segmentation was performed to evaluate medium grain parameter sizes (http:/ /gwyddion.net/download/user-guide/ gwyddion-user-guide-en.pdf, accessed on 30 August 2021). Specific surface segmentations for each kind of ZnTe film surface are presented in Figure 3. In the figure, the violet regions represent water shade masking of deeper film regions where the grain segmentation could not be clearly performed. Grain borders assigned by segmentation are shown in a red-brownish color. The segmentation was performed to identify the largest number of similar-sized grains present on the $2 \mu \mathrm{m} \times 2 \mu \mathrm{m}$ surface scan.
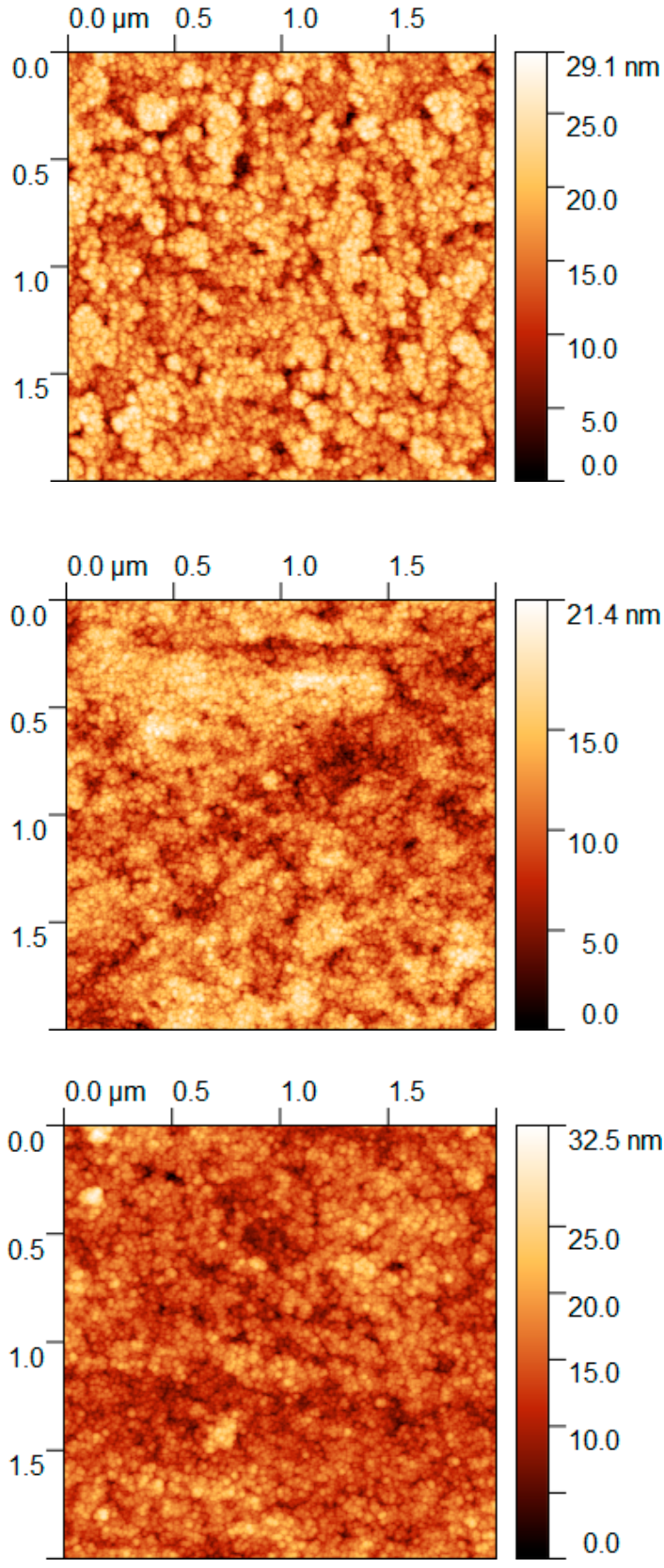

ZnTe1

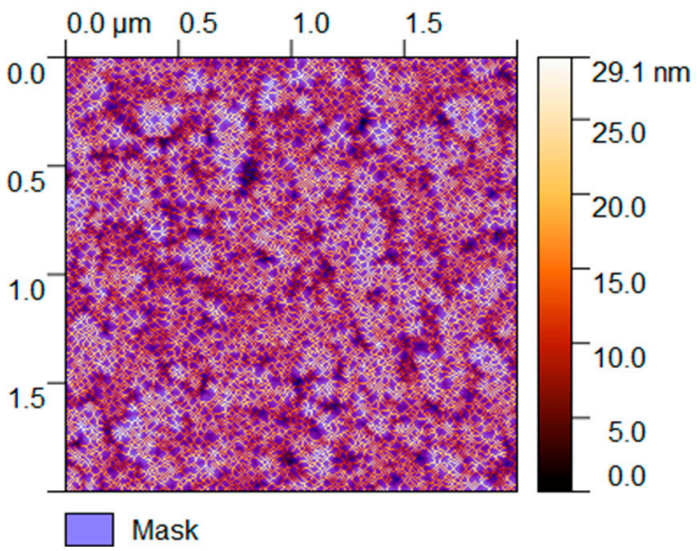

ZnTe2
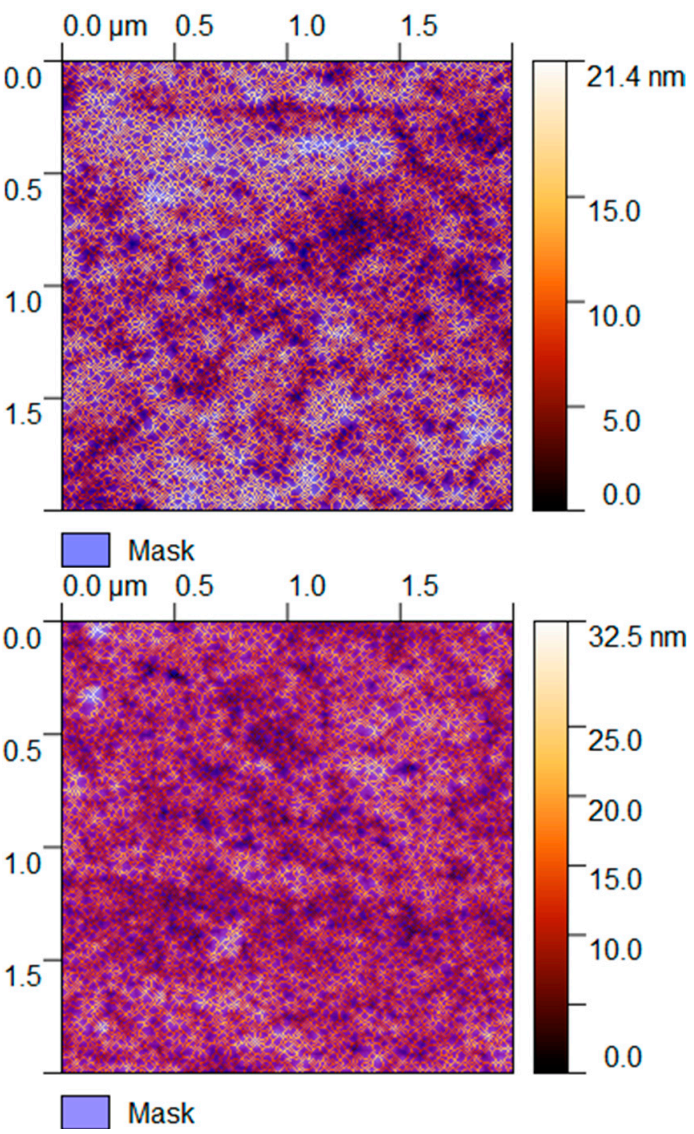

Figure 3. Cont. 

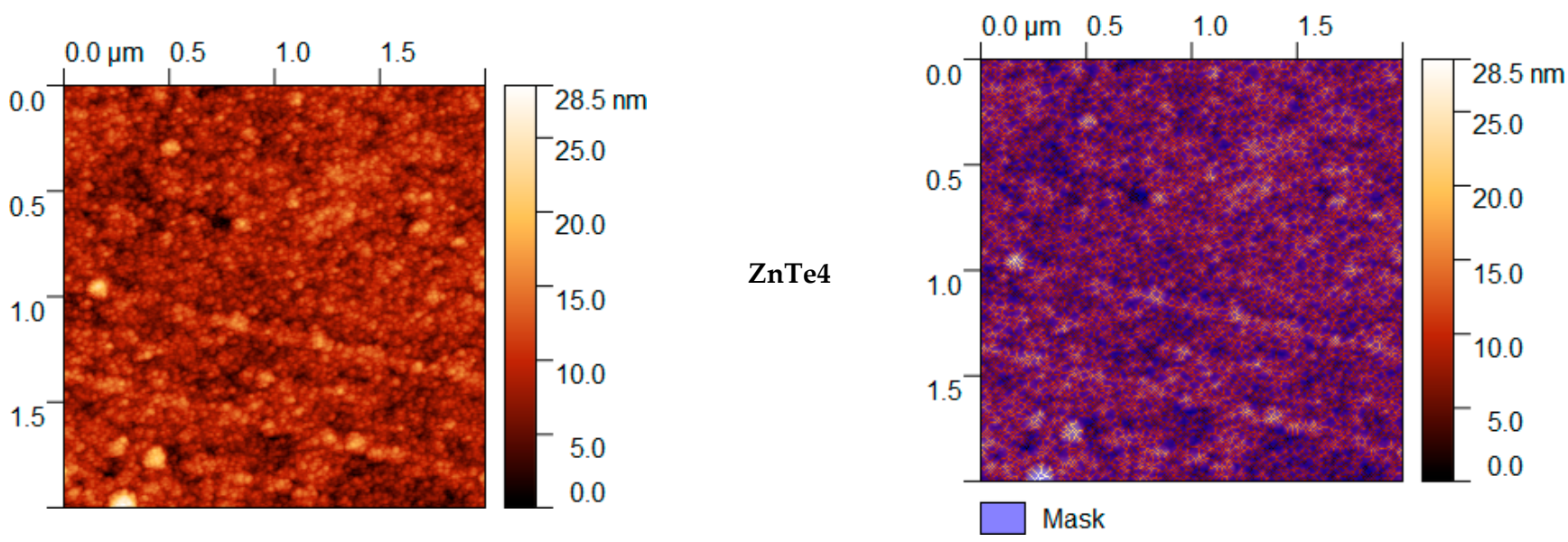

Figure 3. AFM characterization of ZnTe thin films with different thicknesses.

The calculated majoritarian specific parameter size grains are presented in Table 1. These were chosen based on statistical distributions presented in Figures 4-8. The calculus algorithms are open source, available at http:/ /gwyddion.net/download/user-guide/ gwyddion-user-guide-en.pdf, accessed on 30 August 2021.

Table 1. The size and specific parameters for the grains.

\begin{tabular}{cccccccccc}
\hline Sample & $\begin{array}{c}\text { Mean } \\
\text { Surface } \\
\text { Area } \mathbf{m}^{2}\end{array}$ & $\begin{array}{c}\text { Number of } \\
\text { Grains Used } \\
\text { for the Surface } \\
\text { Area } \\
\text { Estimation }\end{array}$ & $\begin{array}{c}\text { Mean } \\
\text { Volume } \\
\mathbf{m}^{\mathbf{3}}\end{array}$ & $\begin{array}{c}\text { Number of } \\
\text { Grains Used } \\
\text { for Volume } \\
\text { Estimation }\end{array}$ & $\begin{array}{c}\text { Grain } \\
\text { Boundaries } \\
\mathbf{n m}\end{array}$ & $\begin{array}{c}\text { Number of } \\
\text { Grains Used } \\
\text { for Grain } \\
\text { Boundaries } \\
\text { Estimation }\end{array}$ & $\begin{array}{c}\text { Mean } \\
\text { Grain } \\
\text { Radius } \\
\text { nm }\end{array}$ & $\begin{array}{c}\text { Number of } \\
\text { Grains } \\
\text { Used for } \\
\text { Grain } \\
\text { Radius } \\
\text { Estimation }\end{array}$ & $\begin{array}{c}\text { Surface } \\
\text { Area/ } \\
\text { Volume } \\
\mathbf{m}^{-1}\end{array}$ \\
\hline ZnTe1 & $4.87 \mathrm{E}-16$ & 6979 & $3.61 \mathrm{E}-26$ & 7163 & 29.37 & 4851 & 9.46 & 5772 & $1.35 \mathrm{E}+10$ \\
\hline ZnTe2 & $4.42 \mathrm{E}-16$ & 7270 & $2.26 \mathrm{E}-24$ & 5773 & 31.36 & 5208 & 9.39 & 5884 & $1.95 \mathrm{E}+8$ \\
\hline ZnTe3 & $5.76 \mathrm{E}-16$ & 7272 & $2.16 \mathrm{E}-25$ & 7442 & 33.97 & 5283 & 9.95 & 6033 & $2.67 \mathrm{E}+9$ \\
\hline ZnTe4 & $4.52 \mathrm{E}-16$ & 7337 & $2.39 \mathrm{E}-24$ & 5432 & 31.59 & 5357 & 9.68 & 6210 & $1.89 \mathrm{E}+8$ \\
\hline
\end{tabular}

Although the surface becomes flatter when the film thickens, it can be observed that the majoritarian grain on the surfaces remained the same, i.e., $\sim 9-10 \mathrm{~nm}$ radius size for all of the films. The projected grain boundary values are also quite close-from 29 to $34 \mathrm{~nm}$, while surface area and grain volumes are obviously more different due to strong surface texturing and a z-range drastic decrease. The surface-to-volume ratio is the amount of the surface area per unit volume of an object or collection of objects; in this case, the grains forming the film surface. It defines the relationship between the structures and functions in processes occurring through the surface and the volume of the film/layer. For the analyzed ZnTe thin films, the estimated surface to volume ratio was highest for the thinner film and was the lowest for the thicker. Additionally, the minimum circumcircle radius for each kind of grain detected on the surfaces, and the mean z-value were estimated for each above-presented AFM image, and are presented in the Figures 4-8. Table 1 presents the mean calculated values for the ZnTe films surface characteristic grains (specific surface area, grain volume, grain boundaries lengths, and surface to volume ratios) that can be further connected with the film growth mechanisms and physical properties. Based on Figures 4-8 that present the dimensional distribution of these surface characteristic parameter values for each of the films, the proper estimation of majoritarian grains is confirmed, and information regarding the other non-majoritarian grains (number and size ranges) present on the samples surfaces is provided. This offers the most complete kind of characterization regarding surface properties of the ZnTe films that one could obtain. 


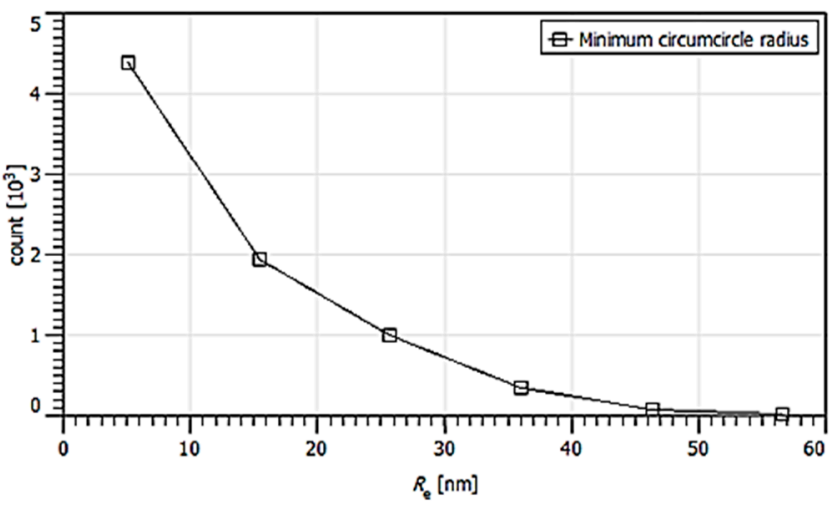

ZnTe1

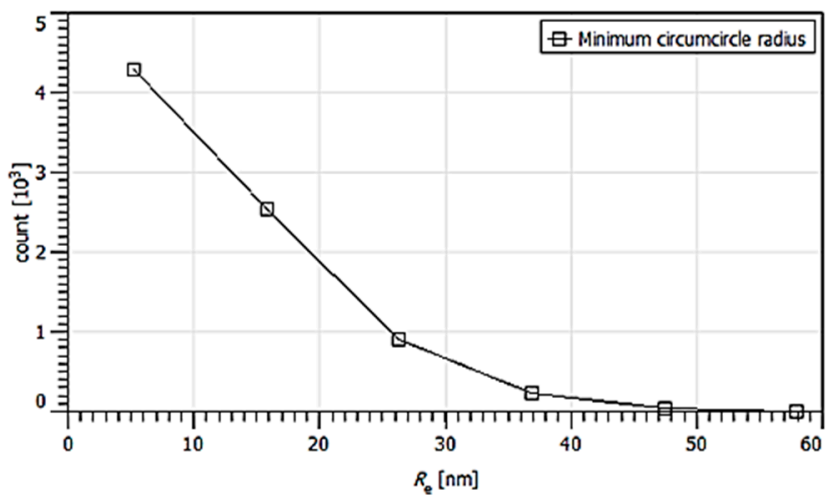

ZnTe2

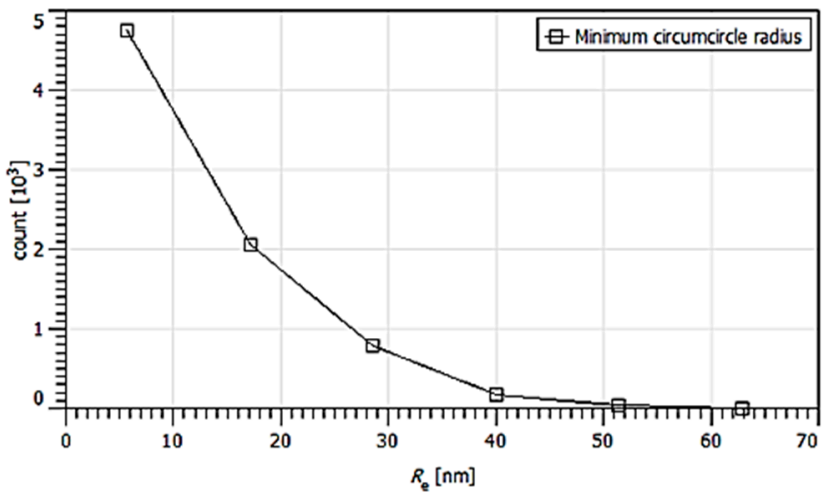

ZnTe3

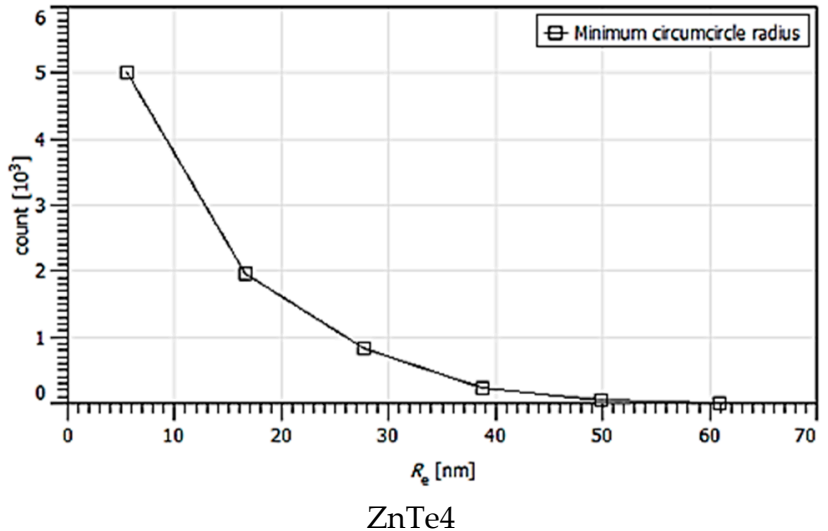

Figure 4. Minimum circumcircle radius value statistic variations onto surfaces of ZnTe1,2,3,4 thin films, presented in AFM images. 

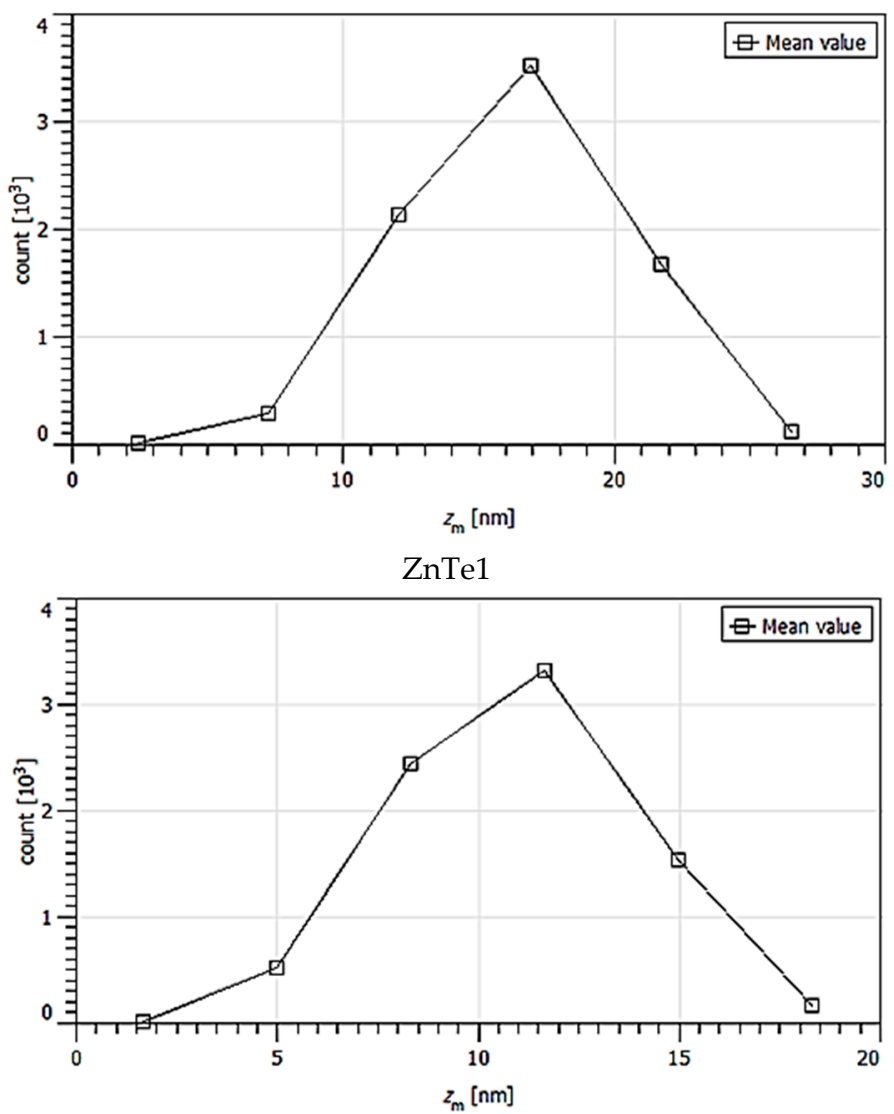

ZnTe2

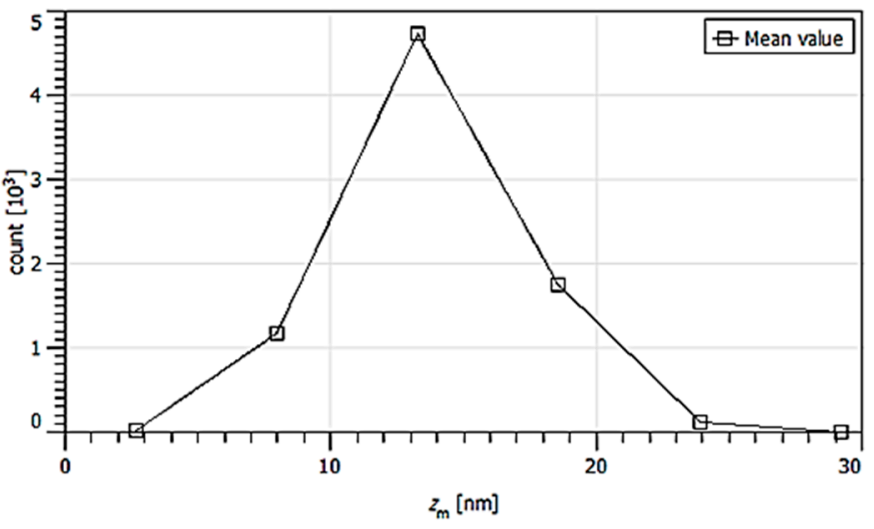

ZnTe3

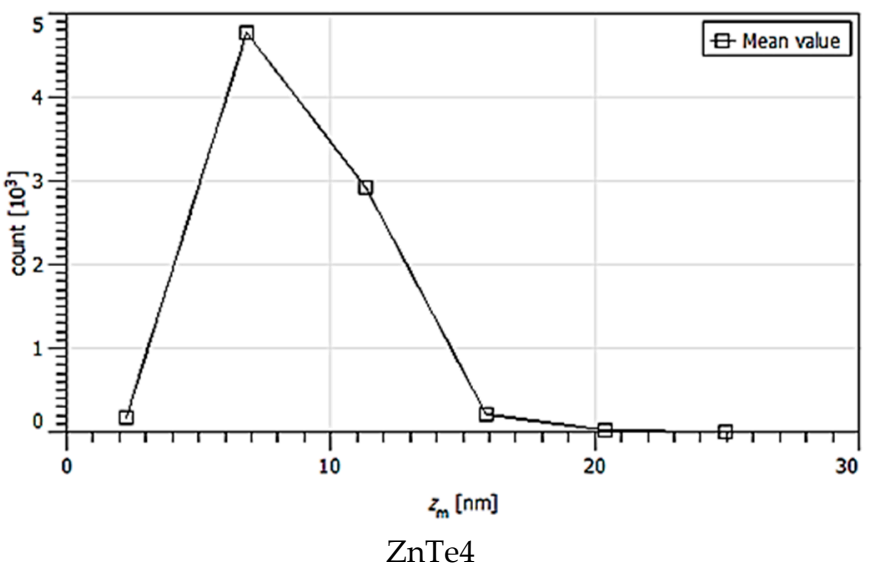

Figure 5. Mean value statistic variation onto surfaces of ZnTe1,2,3,4 thin films. 

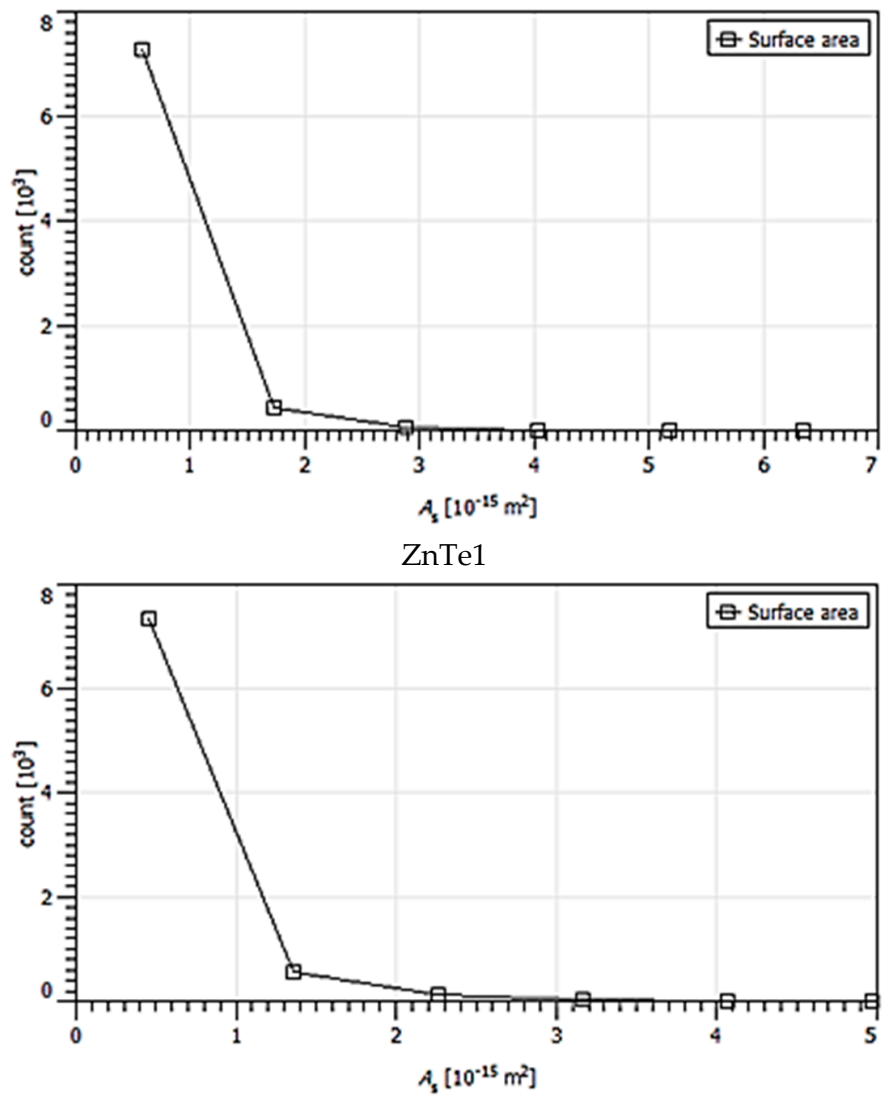

ZnTe2

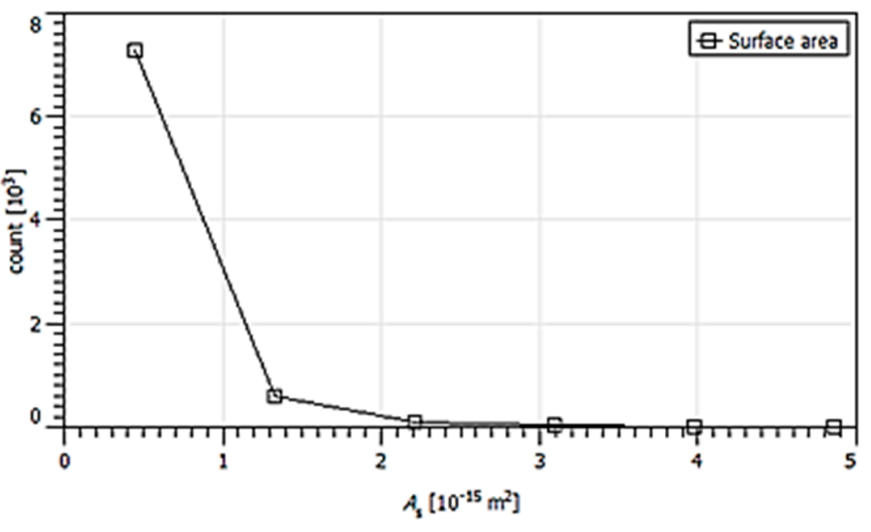

ZnTe3

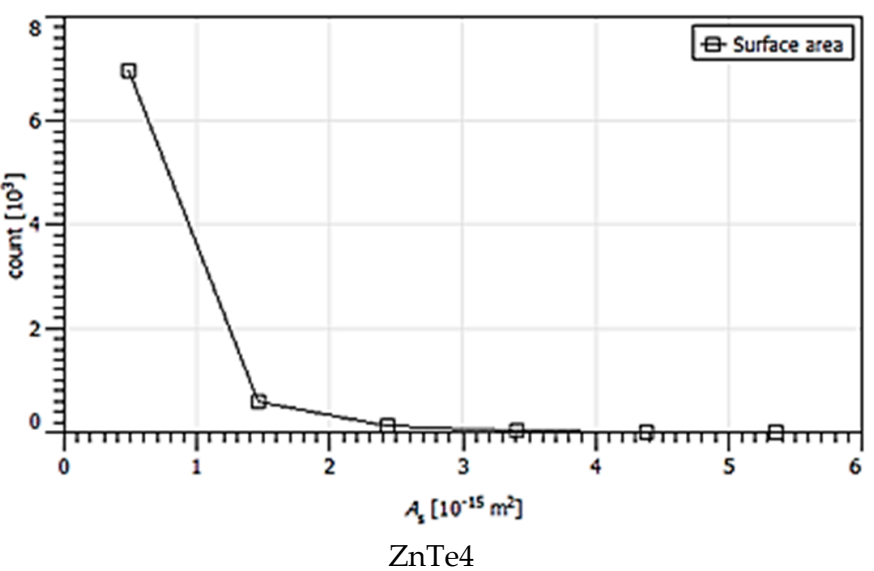

Figure 6. Surface area statistic variation of $\mathrm{ZnTe} 1,2,3,4$ thin films. 

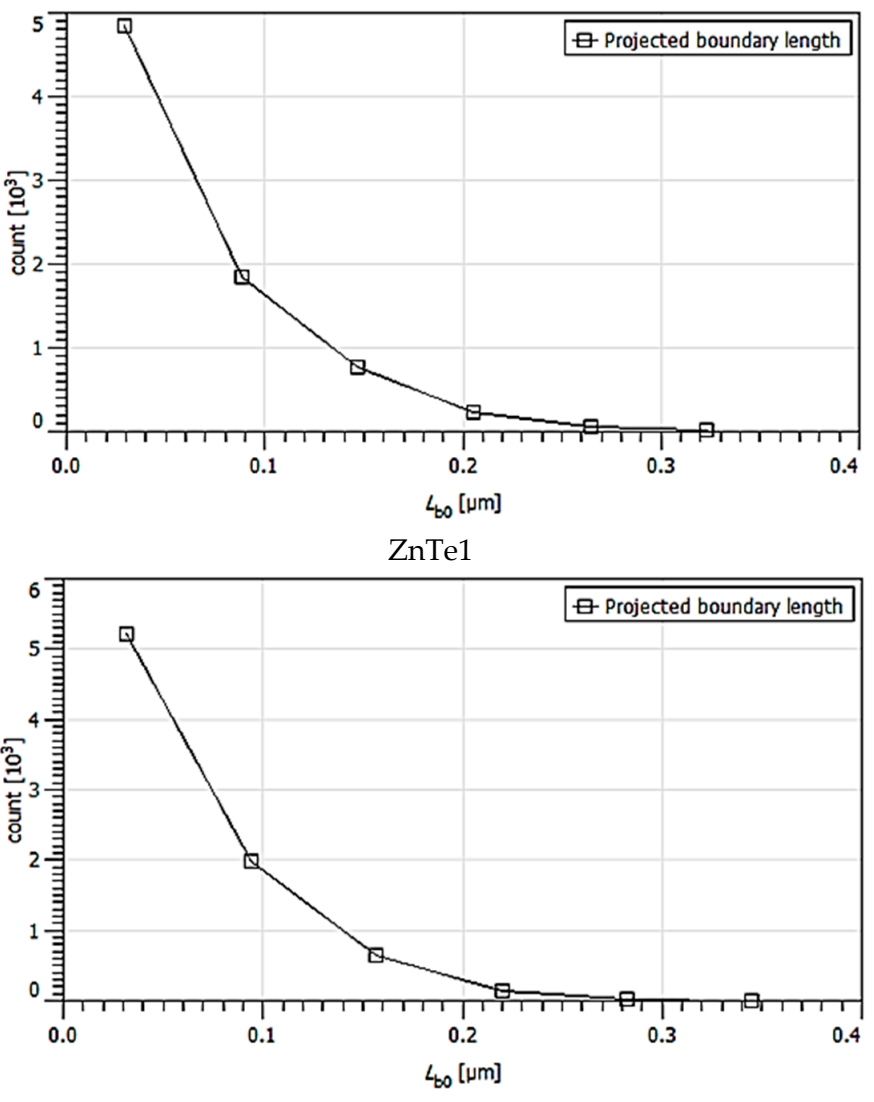

ZnTe2

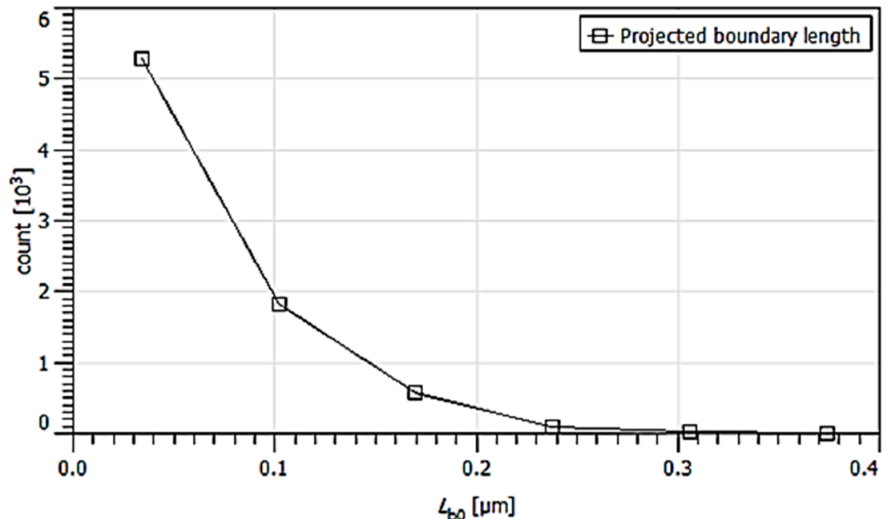

ZnTe3

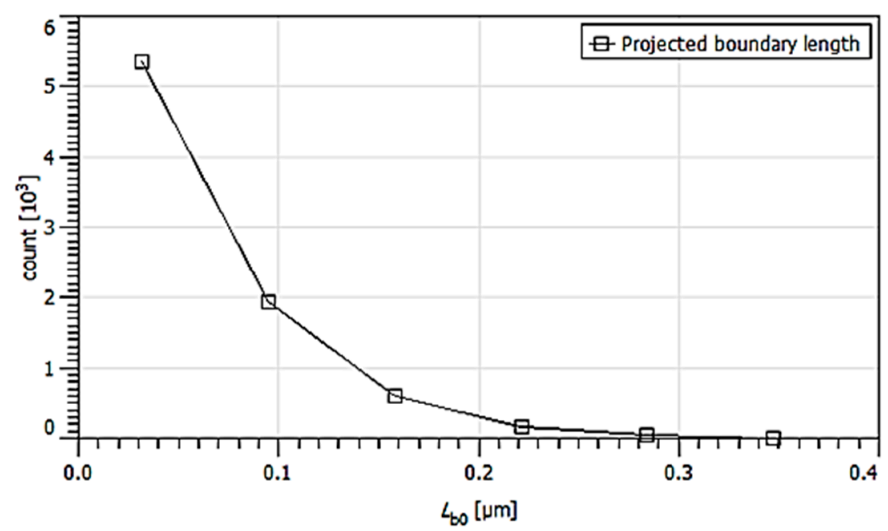

ZnTe4

Figure 7. Projected boundary length statistic variation of ZnTe1,2,3,4 thin films. 


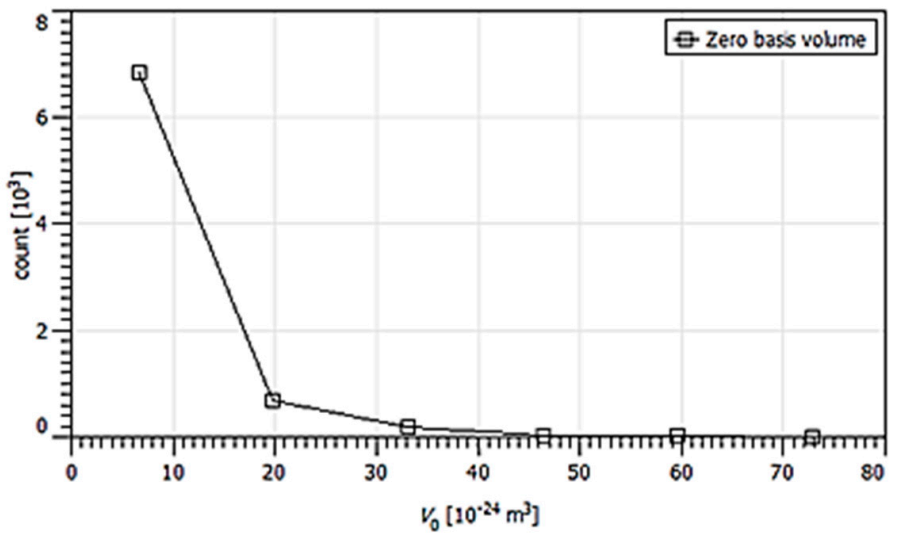

ZnTe1

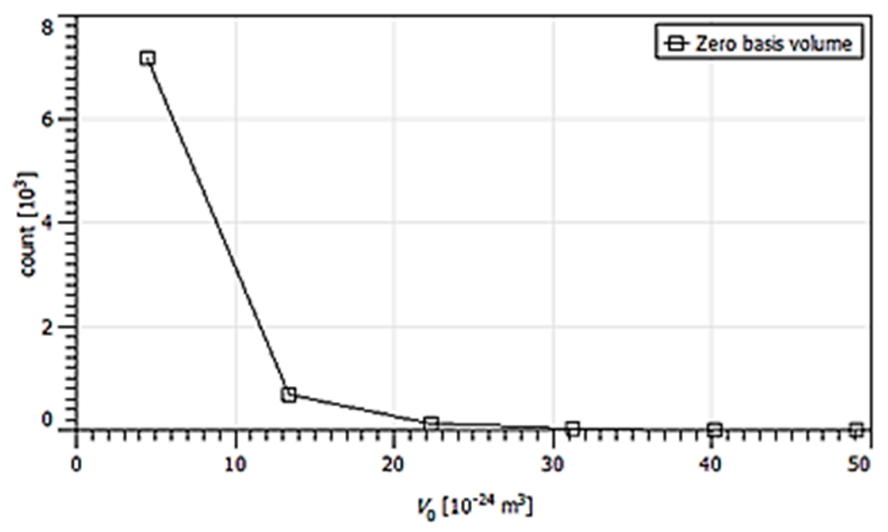

ZnTe2

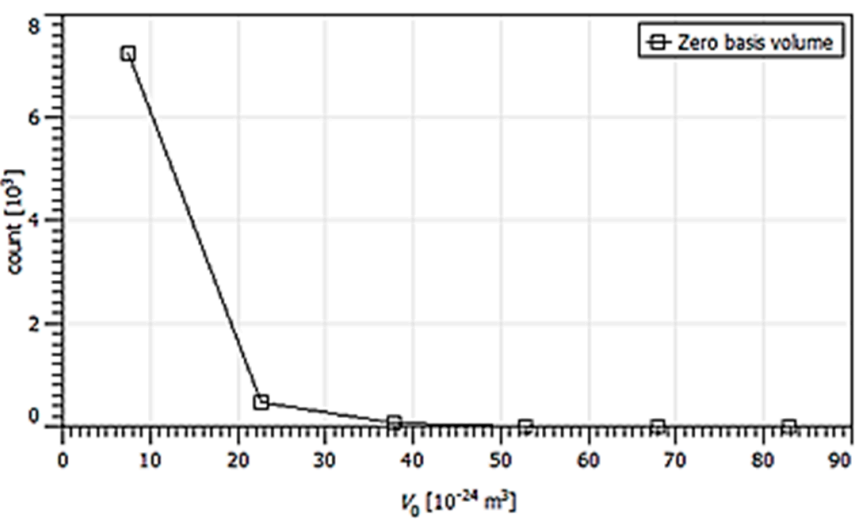

ZnTe3

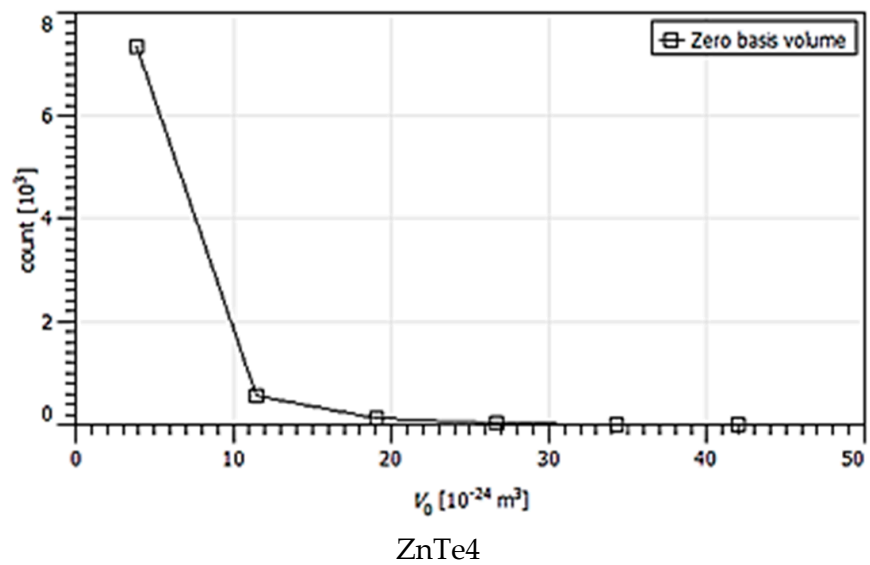

Figure 8. Zero basis volume statistic variation of ZnTe1,2,3,4 thin films. 
The Figures 4-8 show the dimensional distributions of each parameter value onto the $2 \mu \mathrm{m} \times 2 \mu \mathrm{m}$ surface scans (Figure 4 ).

To better analyze the surface roughness evolution, examples of three-dimensional (3D) AFM images of ZnTe films obtained from larger scan sizes $(5 \mu \mathrm{m} \times 5 \mu \mathrm{m})$ are shown in Figure 9. The z-range of the specific 3D representations was chosen to be equal to the highest feature onto the surface, as a better way to observe the regularities and irregularities of the specific surface roughening process determined by film thickening.

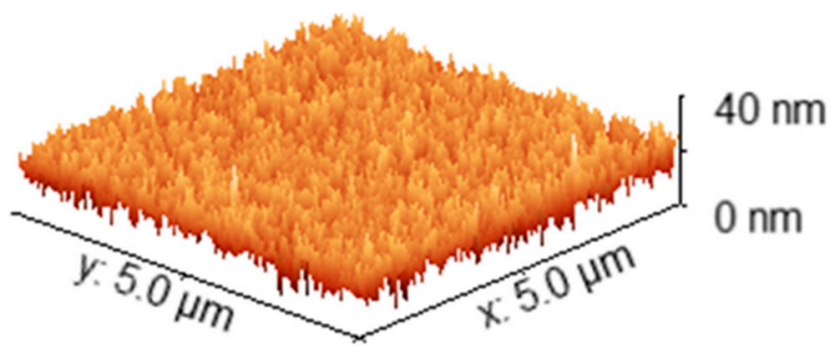

ZnTe1

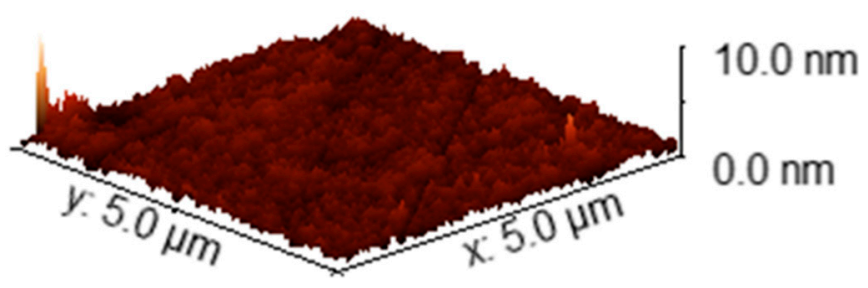

ZnTe2
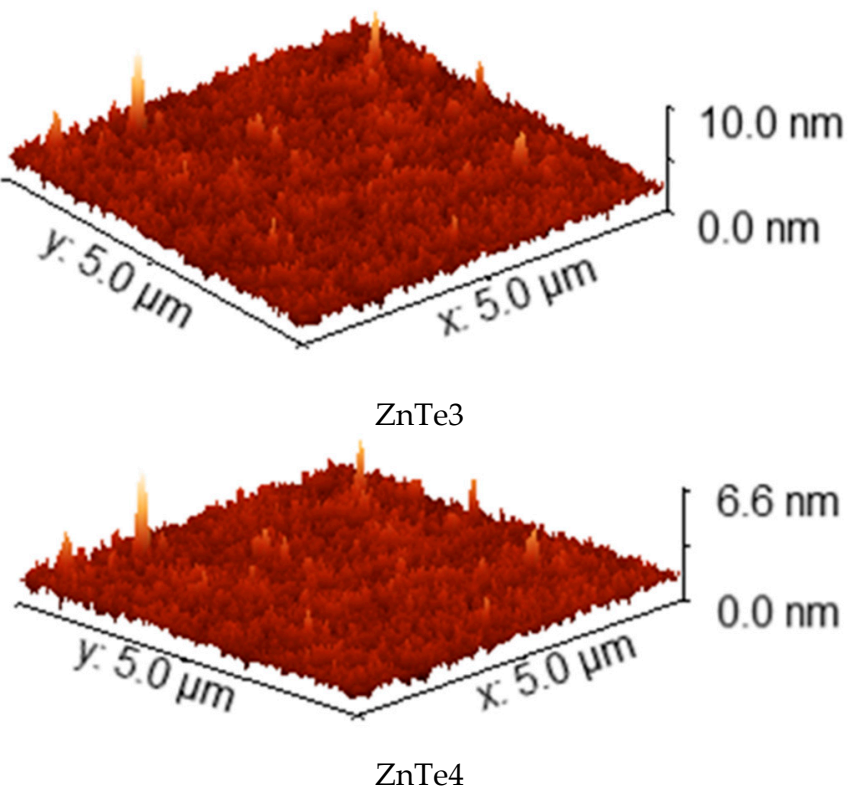

Figure 9. Examples of three-dimensional (3D) AFM images of ZnTe films.

It could be observed that the thicker films exhibit a waviness surface texture while the thinnest show pure grain distribution onto the surface. The growth time effect, onto surface structuring and morphology, is very strong. The thicker ZnTe film surfaces present valley regions, which become relatively smoother as the thickness increases. The cliff regions consist of spike structures that exhibit some orientation. The roughness parameters on surface morphology were estimated by analyzing the $5 \mu \mathrm{m} \times 5 \mu \mathrm{m}$ topography images of the sample surface (Figure 9): average values, peaks, and valleys in the height direction 
$\mathrm{Ra}$, average amplitude in the height direction $\mathrm{Rq}$, and average characteristics in the height direction Rsk.

The average roughness Ra involve peaks and valleys, the mean height measured in the entire area, useful for detecting the profile height sample characteristics. Ra variation typically signifies a change in the growth process. It can be observed that Ra decreases as the film thickness increases. Root mean square (RMS) roughness $\mathrm{Rq}$ is the square root of the standard distribution in the surface profile from the average height. Sq is more sensitive than the average roughness Sa for large deviations from the mean plan and is the most commonly reported measurement of surface roughness. ZnTe thin film thickness increase leads to an $\mathrm{Rq}$ decrease with $\sim 25 \%$. Ten-point mean height roughness (Rz) is a height parameter, the difference between the average of the five highest peaks and five lowest valleys in the sample surface $\mathrm{Rz}$ [26]. Due to the change in surface morphology from uniform granular distribution to a combination of isolated tall grains and tight packaging of grains at increasing thickness, one can see that $\mathrm{Rz}$ varies randomly in our case. Rsk values represent the degree of bias of the roughness shape (asperity). It can be observed that the $\mathrm{Rq}$ and $\mathrm{Ra}$ decrease severely with a film thickness increase, leading to precise determination of skewness Rsk and ten-point mean height roughness $\mathrm{Rz}$, as can be seen in the high deviations in Table 2. The decrease of all surface morphology parameters indicates an inhomogeneity decrease. As the thickness increases, the average roughness Ra and RMS roughness $\mathrm{Rq}$ surface roughness decreases, restricting charged species to be adsorbed on the polycrystalline film. These changes may be related to the rf magnetron sputtering deposition process, which can stimulate the migration of grain boundaries and create more grains during the growth process. Moreover, at a high deposition rate, the supplementary energy encourages the atoms to acquire and occupy the correct site in the crystal lattice, such that the grains with lower surface energy will grow. These correlate well with the XRD observations and the fact that thinner films are amorphous while the thicker become crystalline. Further studies on intermediate growth times will be performed for a better solving of thin film growth mechanism evolution.

Table 2. Calculated roughness parameters on surface morphology.

\begin{tabular}{ccccc}
\hline & ZnTe1 (nm) & ZnTe 2 (nm) & ZnTe 3 (nm) & ZnTe 4 (nm) \\
\hline Rq & 4.08 & 3.45 & 3.29 & 3.09 \\
\hline Grain-wise Rpv & 39.54 & 24.07 & 60.49 & 37.95 \\
\hline Ra & 3.30 & 2.77 & 2.46 & 2.32 \\
\hline Rsk & 0.18 & 0.04 & -1.33 & -0.92 \\
\hline Rz & 36.32 & 23.52 & 54.33 & 36.03 \\
Rku & 2.87 & 2.79 & 14.55 & 6.13 \\
\hline
\end{tabular}

\subsection{Optical Characterization}

\subsubsection{Ellipsometry}

Ellipsometry measurements were performed onto all ZnTe samples. Using the WVASE 32 software package, the simulation of the theoretical curves was performed. The obtained parameters were $\Psi$ and $\Delta$ in the spectral range $250-1700 \mathrm{~nm}$, scanning with a step of $2 \mathrm{~nm}$. The analysis of the samples was performed at three incidence angles $\left(60^{\circ}, 65^{\circ}\right.$, and $\left.70^{\circ}\right)$ with a step of $5^{\circ}$ as described in references [27-30]. A ZnTe semiconductor model was selected according to the reference [30] for better measurement of bandwidth absorption, which is very important for the design of solar cells [29]. These aspects demonstrate the complexity of the thin film structures and influence of $n, k$ parameters for many A2-B6 compounds [31-35]. As for the SE system, it was equipped with software for control and simulation of theoretical curves using a theoretical model [28]. The optical model was elaborated based on three layers: glass substrate, the ZnTe layer simulated using the Zinc telluride mathematical model in the WVASE database,, adjusting the thickness to fit the 
data, and the third layer-"srough". The zinc telluride mathematical model in the V VASE database is a GenOsc Tauc-Lorentz model. The model is fitted to minimize the mean square error (MSE) and reach a normal fit. Normal fit is reached by iterative approximations. The number of required iterations differs for each of the samples. Details regarding the simulation steps and models can be found in [27]. Film thickness and film roughness vary due to growth conditions. The scanning of the samples ( $\mathrm{ZnTe})$ and the substrate (BK7 Glass) were performed followed by the simulation of the theoretical curves with the help of the software, as can be seen from the examples presented in Figure 10.

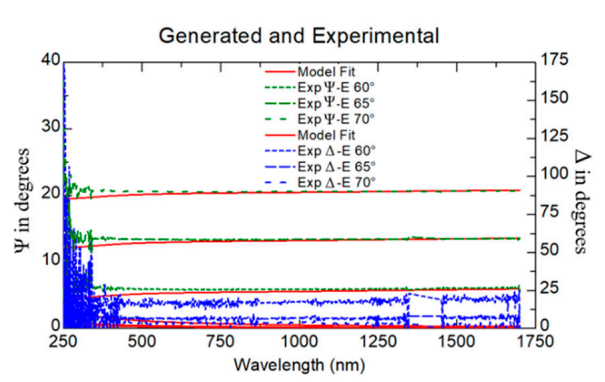

1 srough

0 bk7
$0.558 \mathrm{~nm}$

$1 \mathrm{~mm}$

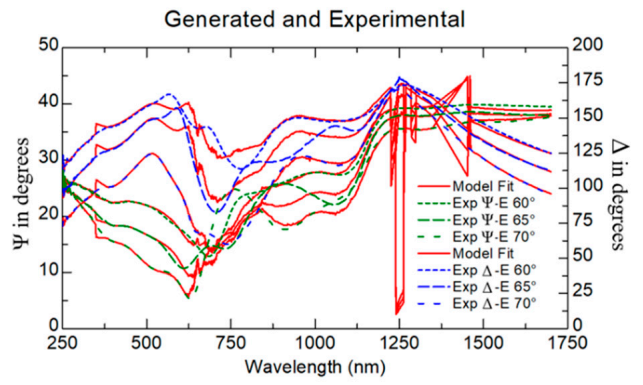

2 srough

$1 \mathrm{ZnTe1}$ (5')

0 bk7

$0.000 \mathrm{~nm}$

$6.965 \mathrm{~nm}$

$1 \mathrm{~mm}$

\section{Substrate}

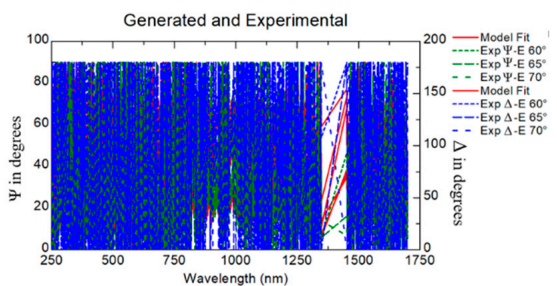

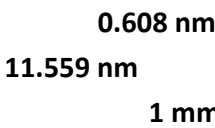

$1 \mathrm{~mm}$

ZnTe2 (10')

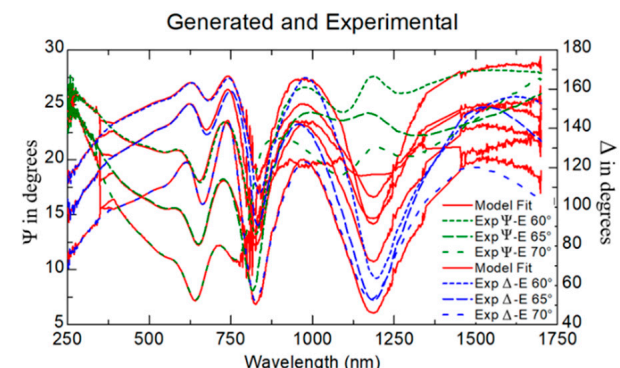

2 srough

$1 \mathrm{ZnTe} 4$ (20')

0 bk7

ZnTe4 (20')
ZnTe1 (5')

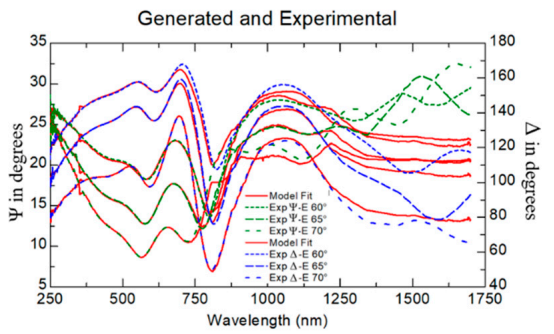
2 srough
$1 \mathrm{ZnTe} 3$ (15')
0 bk7
ZnTe3 (15')

$7.215 \mathrm{~nm}$

$7.620 \mathrm{~nm}$
$1 \mathrm{~mm}$

Figure 10. Theoretical and experimental ellipsometry data ( $\Delta$ and $\Psi)$ of $\mathrm{ZnTe}$ thin films at three incidence angles. 
Figure 10 presents the SE measurements and theoretical modeling at three incidence angles $\left(60^{\circ}, 65^{\circ}\right.$, and $\left.70^{\circ}\right)$ in the spectral range $250-1750 \mathrm{~nm}$ for estimation of optical roughness of the substrate and the ZnTe films analyzed during this study. Good qualitative agreement was found between the SE measurements and the theoretical simulations. The fitted SE spectra deviate significantly from the measured ones for the thinner films. These differences may be associated with the deviations of film stoichiometry and crystallinity in the various stages of growth from the ideal models. The differences are smaller for the thicker films. Further studies for better correlations are ongoing.

Table 3 represents a comparative presentation of the roughness measured by SE and RMS measured by AFM. The observed difference is generated by the different measurement principles of SE and AFM. SE measures the effect of roughness at the atomic size. The value of the RMS roughness is influenced from the peak to the height of the valley being approximately twice as high as the one estimated by SE measurements.

Table 3. Surface roughness measured by SE and AFM on ZnTe samples that have different deposition times.

\begin{tabular}{|c|c|c|c|c|c|c|c|}
\hline \multirow[t]{2}{*}{ Sample } & \multirow{2}{*}{$\begin{array}{c}\text { Type of } \\
\text { Substrate }\end{array}$} & \multirow{2}{*}{$\begin{array}{l}\text { Deposition } \\
\text { Time (min) }\end{array}$} & \multirow{2}{*}{$\begin{array}{l}\text { Roughness } \\
\text { Measured by } \\
\text { SE (nm) }\end{array}$} & \multicolumn{2}{|c|}{$\begin{array}{l}\text { RMS Roughness } \\
\text { AFM (nm) }\end{array}$} & \multirow{2}{*}{$\begin{array}{c}\text { Thickness } \\
\text { Nonuniformity } \\
(\%)\end{array}$} & \multirow[t]{2}{*}{ MSE } \\
\hline & & & & $2 \times 2 \mu \mathrm{m}^{2}$ & $5 \times 5 \mu \mathrm{m}^{2}$ & & \\
\hline ZnTe1 (5') & BK7 & 5 & 0.000 & 4.2 & 4.1 & $38.851 \%$ & 15.01 \\
\hline ZnTe2 (10') & BK7 & 10 & 0.608 & 3.1 & 3.5 & $63.064 \%$ & 0.2747 \\
\hline ZnTe3 (15') & BK7 & 15 & 7.215 & 3.4 & 3.3 & $100 \%$ & 7.693 \\
\hline ZnTe4 (20') & BK7 & 20 & 4.982 & 2.5 & 3 & $100 \%$ & 19.55 \\
\hline
\end{tabular}

\subsubsection{Optical Spectroscopy and Bandgap}

To study the optical properties of the fabricated samples, UV-Vis absorption measurements were performed. The UV-Vis absorption spectra of each sample, as well as the extrapolation used to calculate their optical bandgap using Tauc plots were obtained. Since $\mathrm{ZnTe}$ is a direct bandgap semiconductor, $(\alpha \mathrm{hv})^{2}$ was used to calculate the bandgaps. Representative examples of some absorption spectra and Tauc plots derived from the ZnTe thin film analysis are presented in Figure 11.
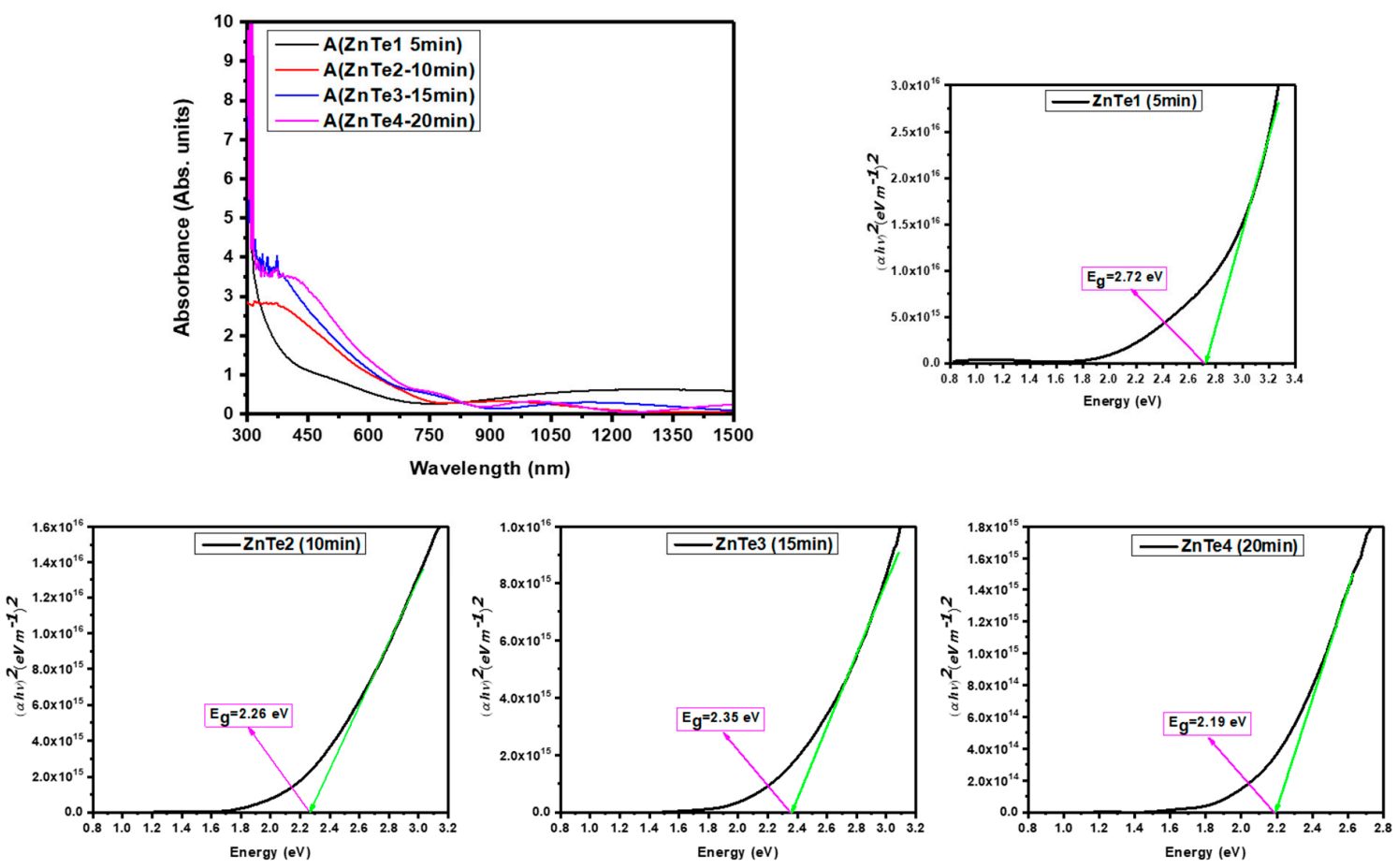

Figure 11. Examples of UV-Vis absorption spectra and of optical bandgap energy estimation using Tauc Plots. 
Bandgap energy (Eg) values obtained for the optimized materials are presented in Table 4.

Table 4. Bandgap values.

\begin{tabular}{cc}
\hline Sample & Bandgap Eg(eV) \\
\hline ZnTe1 & 2.72 \\
\hline ZnTe2 & 2.26 \\
\hline ZnTe3 & 2.35 \\
\hline ZnTe4 & 2.19 \\
\hline
\end{tabular}

It was observed that the increased thickness leads to a decrease of optical transmittance in the visible region and the presence of the fringes in the NIR region of the electromagnetic spectrum (see Figure 12). The calculated bandgap values slightly decrease with the thickness increase.

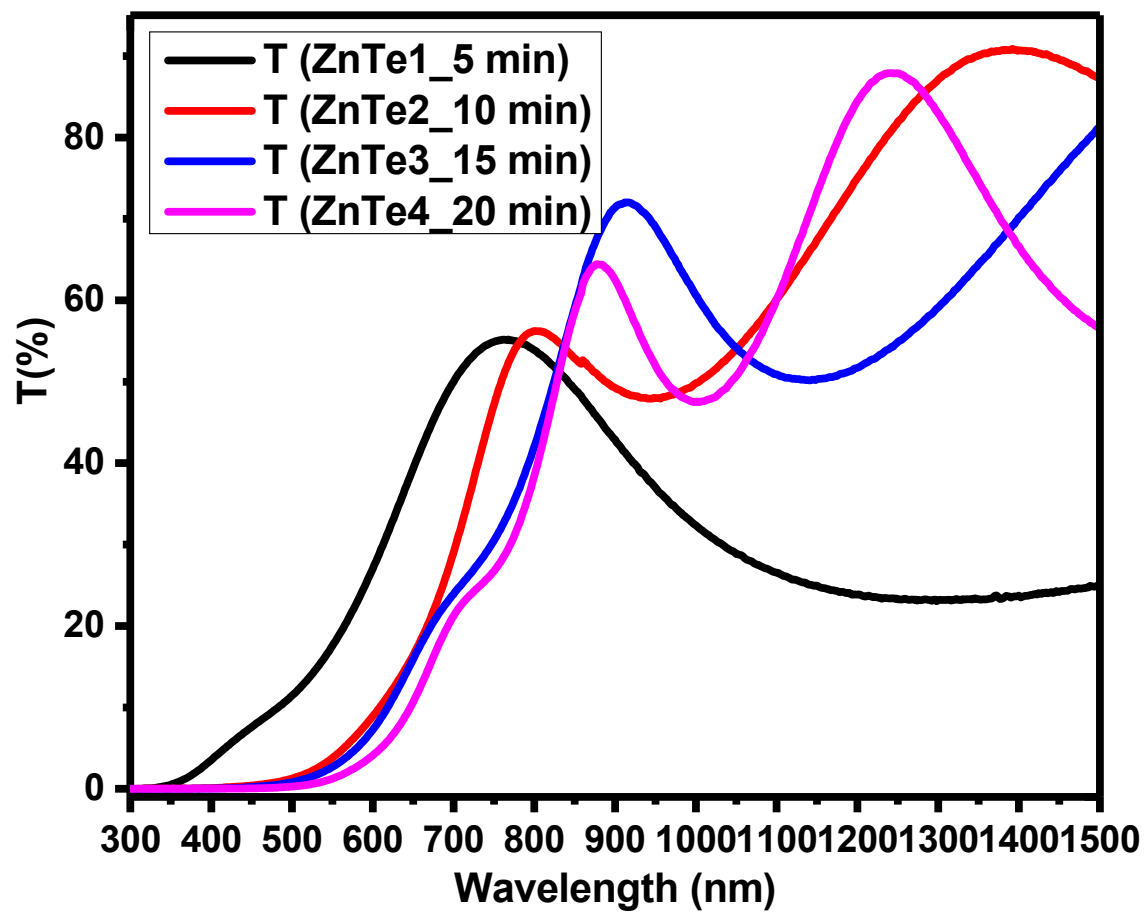

Figure 12. UV-Vis transmission spectroscopy spectra of ZnTe thin films with different thicknesses.

\section{Conclusions and Perspectives}

ZnTe thin films with different thicknesses on BK7 glass substrates were grown by the rf magnetron sputtering technique, using time as a variable growth parameter. All other deposition process parameters were kept constant. The fabricated thin films with mean thickness, ranging from 75 to $461 \mathrm{~nm}$, were characterized using electron microscopy, X-rays diffraction, atomic force microscopy, ellipsometry, and UV-Vis spectroscopy, to evaluate their structures, surface morphology, topology, and optical properties. By using SEM to measure the obtained film thickness, it was found that the deposition time increase leads to a larger growth rate. This determines significant changes on ZnTe thin film structuring and surface morphology. Characteristic surface metrology parameter values vary, and surface texturing evolves with thickness increase, correlating well with XRD analysis findings that thinner films are amorphous, and at least $10 \mathrm{~min}$ of growth is needed for the crystalline material to start to form. Larger thickness films show diffraction peaks located at $25.24^{\circ}, 42.34^{\circ}$, and $49.59^{\circ}$, which corresponds unambiguously to (111), (220), and (311) reflections of the cubic ZnTe phase, according to the JCPDS database with card no. 01-0582. For these films, the mean crystallite sizes are $\sim 5$ and $\sim 9 \mathrm{~nm}$, smaller than the surface grain size, estimated from the AFM analysis to be $\sim 9 \mathrm{~nm}$ radius, i.e., $\sim 18 \mathrm{~nm}$ 
diameter. The crystallite size shows values comparable to the ZnTe exciton radius estimated at $\sim 6-7 \mathrm{~nm}$ [36], fact that opens interesting supplementary research perspective on size quantum effects on optical properties of such ZnTe films grown onto various substrates. Optical bandgap energy values slightly decrease as the thickness increases, while the mean grain radius remains almost constant at $\sim 9 \mathrm{~nm}$ and the surface to volume ratio per grain decreases by two orders of magnitude. To our knowledge, this study is the first attempt that thoroughly considers the correlation of film thickness with ZnTe structuring and surface morphology characteristic parameters. It adds value to the existing knowledge on ZnTe thin film fabrication and their physical properties, tailored for various applications, including photovoltaics. There are ongoing studies regarding the correlation between structure and surface morphology, with the observed optical properties; this will lead to future scientific reports.

Author Contributions: Conceptualization, S..A.; methodology, S..A.; formal analysis, L.I., V.-A.A., S.I., M.P.S.; investigation, D.M., V.-A.A., S.I., A.M., R.P. and Ş.A.; resources, V.-A.A., S.I., M.P.S.; writing-original draft preparation, D.M., S.I.; M.P.S. and V.-A.A.; writing-review and editing, M.P.S. and S..A.; supervised and coordinated the experimental work. All authors have read and agreed to the published version of the manuscript.

Funding: This research was funded by the "Executive Unit for Financing Higher Education, Research, Development and Innovation" (UEFISCDI, Romania), through grants: PN-III-P1-1.1-TE-2019-0868 (TE 115/2020) and PN-III-P1-1.1-TE-2019-0846 (TE 25/2020). M.P.S. contribution was partially financed by the Romanian Ministry of Research, Innovation and Digitalisation thorough "MICRONANO-SIS PLUS" core Programme.

Institutional Review Board Statement: Not applicable.

Informed Consent Statement: Not applicable.

Data Availability Statement: The raw and processed data required to reproduce these findings cannot be shared at this time due to technical or time limitations. The raw and processed data will be provided upon reasonable request to anyone interested anytime, until the technical problems will be solved.

Acknowledgments: D.M. thanks Cosmin Romanitan from IMT Bucharest for valuable advice on XRD data analysis.

Conflicts of Interest: The authors declare no conflict of interest. The funders had no role in the design of the study; in the collection, analyses, or interpretation of data; in the writing of the manuscript, or in the decision to publish the results.

\section{References}

1. Rusu, G.I.; Prepeliţă, P.; Rusu, R.S.; Apetroaie, N.; Oniciuc, G.; Amariei, A. On the structural and optical characteristics of zinc telluride thin films. J. Optoelectron. Adv. Mater. 2006, 8, 922-926.

2. Rathod, J.R.; Patel, H.S.; Patel, K.D.; Pathak, V.M. Structural and Optical Characterization of Zinc Telluride Thin Films. Adv. Mater. Res. 2013, 665, 254-262. [CrossRef]

3. Shanmugan, S.; Mutharasu, D. Optical Properties and Surface Morphology of Zinc Telluride Thin Films Prepared by Stacked Elemental Layer Method. Mater. Sci. 2012, 18, 107-111. [CrossRef]

4. Sun, J.; Shen, Y.; Chen, R.; Huang, J.; Cao, M.; Gu, F.; Wang, L.; Min, J. Effect of ZnTe transition layer to the performance of CdZnTe/GaN multilayer films for solar-blind photodetector applications. J. Phys. D Appl. Phys. 2020, 53, 415105. [CrossRef]

5. Suthar, D.; Himanshu; Patel, S.L.; Chander, S.; Kannan, M.D.; Dhaka, M.S. Enhanced physicochemical properties of ZnTe thin films as potential buffer layer in solar cell applications. Solid State Sci. 2020, 107, 106346. [CrossRef]

6. Zarei, R.; Ehsani, M.H.; Dizaji, H.R. An investigation on structural and optical properties of nanocolumnar ZnTe thin films grown by glancing angle technique. Mater. Res. Express 2020, 7, 026419. [CrossRef]

7. Isik, M.; Gullu, H.H.; Parlak, M.; Gasanly, N.M. Synthesis and temperature-tuned band gap characteristics of magnetron sputtered ZnTe thin films. Phys. B Condens. Matter 2020, 582, 411968. [CrossRef]

8. Toma, O.; Ion, L.; Iftimie, S.; Antohe, V.A.; Radu, A.; Raduta, A.M.; Manica, D.; Antohe, S. Physical properties of rf-sputtered ZnS and ZnSe thin films used for doubleheterojunction ZnS/ZnSe/CdTe photovoltaic structures. Appl. Surf. Sci. 2019, 478, 831-839. [CrossRef]

9. Maki, S.A.; Hanan, H.K. The Structural and Optical Properties of Zinc Telluride Thin Films by Vacuum Thermal Evaporation Technique. Ibn AL-Haitham J. Pure Appl. Sci. 2017, 29, 70-80. 
10. Ikhioya, I.L. Optical and electrical properties of znte thin films using electrodeposition technique. Int. J. Innov. Appl. Stud. 2015, 12, 369-373.

11. Li, J.; Diercks, D.R.; Ohno, T.R.; Warren, C.W.; Lonergan, M.C.; Beach, J.D.; Wolden, C.A. Controlled activation of ZnTe: Cu contacted CdTe solar cells using rapid thermal processing. Sol. Energy Mater. Sol. Cells 2015, 133, 208-215. [CrossRef]

12. Gessert, T.A.; Asher, S.; Johnston, S.; Young, M.; Dippo, P.; Corwine, C. Analysis of CdS/CdTe devices incorporating a ZnTe:Cu/Ti Contact. Thin Solid Film. 2007, 515, 6103-6106. [CrossRef]

13. Lopez, J.D.; Tirado-Mejia, L.; Ariza-Calderon, H.; Riascos, H.; de Anda, F.; Mosquera, E. Structural and optical properties of gadolinium doped ZnTe thin films. Mater. Lett. 2020, 268, 127562. [CrossRef]

14. Bhahada, K.C.; Tripathi, B.; Acharya, N.K.; Kulriya, P.K.; Vijay, Y.K. Formation of ZnTe by stacked elemental layer method. Appl. Surf. Sci. 2008, 255, 2143-2148. [CrossRef]

15. Pfisterer, F.; Schock, H.W. ZnTe-CdS Thin-Film photo-voltaic cells. J. Cryst. Growth 1982, 59, 432-439. [CrossRef]

16. Naifar, A.; Zeiri, N.; Nasrallah, S.A.-B.; Said, M. Optical properties of CdSe/ZnTe type II core shell nanostructures. Optik 2017, 146, 90-97. [CrossRef]

17. Mahmood, W.; Shah, N.A. Effects of metal doping on the physical properties of ZnTe thin films. Curr. Appl. Phys. 2014, 14, 282-286. [CrossRef]

18. Wolden, C.A.; Abbas, A.; Li, J.; Diercks, D.R.; Meysing, D.M.; Ohno, T.R.; Beach, J.D.; Barnes, T.M.; Walls, J.M. The roles of ZnTe buffer layers on CdTe solar cell performance. Sol. Energy Mater. Sol. Cells 2016, 147, 203-210. [CrossRef]

19. Ogawa, H.; Irfan, G.S.; Nakayama, H.; Nishio, M.; Yoshida, A. Growth of low resistivity n-type ZnTe by metalorganic vapor phase epitaxy. Jpn. J. Appl. Phys. 1994, 33, L980-L982. [CrossRef]

20. Rehman, K.M.U.; Liu, X.S.; Riaz, M.; Yang, Y.J.; Feng, S.J.; Khan, M.W.; Ahmad, A.; Shezad, M.; Wazir, Z.; Ali, Z.; et al. Fabrication and characterization of Zinc Telluride (ZnTe) thin films grown on glass substrates. Phys. B Condens. Matter 2019, 560, $204-207$. [CrossRef]

21. Chang, J.H.; Takai, T.; Koo, B.H.; Song, J.S.; Handa, T.; Yao, T. Aluminum-doped n-type ZnTe layers grown by molecular-beam epitaxy. Appl. Phys. Lett. 2001, 79, 785-787. [CrossRef]

22. Mahalingam, T.; John, V.S.; Rajendran, S.; Sebastian, P.J. Electrochemical deposition of ZnTe thin films. Semicond. Sci. Technol. 2002, 17, 465-470. [CrossRef]

23. Structural and Optical Properties of ZnTe Thin Films Induced by Plasma Immersion O-ion Implantation. Available online: https:/ / www.semanticscholar.org/paper/Structural-and-optical-properties-of-ZnTe-thin-by-O-Aboraia-Ahmad/b4307edf5 d7445fb79363dbe93d32cd0ac20a88a (accessed on 30 August 2021).

24. Patterson, A.L. The Scherrer Formula for X-ray Particle Size Determination. Phys. Rev. 1939, 56, 978-982. [CrossRef]

25. Waseda, Y.; Matsubara, E.; Shinoda, K. X-ray Diffraction Crystallography: Introduction, Examples and Solved Problems; Springer: Berlin/Heidelberg, Germany, 2011. [CrossRef]

26. Available online: http://gwyddion.net/documentation/user-guide-en/roughness-iso.html (accessed on 30 August 2021).

27. J.A. Woollam Co., Inc. VASE®Specifications-Technical Specifications. 2007. Available online: https://www.jawoollam.com/ download/pdfs/vase-brochure.pdf (accessed on 30 August 2021).

28. Fujiwara, H. Spectroscopic Ellipsometry: Principles and Applications; John Wiley Sons: Hoboken, NJ, USA, 2007.

29. Potlog, T.; Maticiuc, N.; Mirzac, A.; Dumitriu, P.; Scortescu, D. Structural and optical properties of ZnTe thin films. In Proceedings of the CAS 2012 (International Semiconductor Conference), Sinaia, Romania, 15-17 October 2012; pp. 321-324. [CrossRef]

30. Toma, O.; Pascu, R.; Dinescu, M.; Besleaga, C.; Mitran, T.L.; Scarisoreanu, N.; Antohe, S. Growth and Characterization of Nanocrystalline CdS Thin Films. Chalcogenide Lett. 2011, 8, 541-548.

31. Antohe, S.; Ion, L.; Girtan, M.; Toma, O. Optical and morphological studies of thermally vacuum evaporated ZnSe thin films. Rom. Rep. Phys. 2013, 65, 805-811.

32. Ion, L.; Iftimie, S.; Radu, A.; Antohe, V.A.; Toma, O.; Antohe, S. Physical properties of RF-sputtered ZnSe thin films for photovoltaic applications: Influence of film thickness. Proc. Rom. Acad. Ser. A 2021, 22, 25-34.

33. Toma, O.; Ion, L.; Iftimie, S.; Radu, A.; Antohe, S. Structural, morphological and optical properties of rf-Sputtered CdS thin films. Mater. Des. 2016, 100, 198-203. [CrossRef]

34. Toma, O.; Ion, L.; Girtan, M.; Antohe, S. Optical, morphological and electrical studies of thermally vacuum evaporated CdTe thin films for photovoltaic applications. Sol. Energy 2014, 108, 51-60. [CrossRef]

35. Ruxandra, V.; Antohe, S. The effect of the electron irradiation on the electrical properties of thin polycrystalline CdS layers. $J$. Appl. Phys. 1998, 84, 727-733. [CrossRef]

36. Yoffe, A.D. Low-dimensional systems: Quantum size effects and electronic properties of semiconductor microcrystallites (zero-dimensional systems) and some quasi-two-dimensional systems. Adv. Phys. 1993, 42, 173-262. [CrossRef] 